University of Louisville

ThinkIR: The University of Louisville's Institutional Repository

Electronic Theses and Dissertations

$5-2015$

\title{
The influence of child physical activity programs on parent physical activity in a rural community.
}

Katie F. Leslie

University of Louisville

Follow this and additional works at: https://ir.library.louisville.edu/etd

Part of the Public Health Commons

\section{Recommended Citation}

Leslie, Katie F., "The influence of child physical activity programs on parent physical activity in a rural community." (2015). Electronic Theses and Dissertations. Paper 2027.

https://doi.org/10.18297/etd/2027

This Doctoral Dissertation is brought to you for free and open access by ThinkIR: The University of Louisville's Institutional Repository. It has been accepted for inclusion in Electronic Theses and Dissertations by an authorized administrator of ThinkIR: The University of Louisville's Institutional Repository. This title appears here courtesy of the author, who has retained all other copyrights. For more information, please contact thinkir@louisville.edu. 
THE INFLUENCE OF CHILD PHYSICAL ACTIVITY PROGRAMS ON PARENT PHYSICAL ACTIVITY IN A RURAL COMMUNITY

\author{
By \\ Katie F. Leslie \\ B.S., University of Kentucky, 2007 \\ M.S., University of Louisville, 2008 \\ A Dissertation \\ Submitted to the Faculty of the \\ School of Public Health and Information Sciences of the University of Louisville \\ in Partial Fulfillment of the Requirements \\ for the Degree of \\ Doctor of Philosophy in Public Health Sciences \\ Department of Health Promotion and Behavioral Sciences \\ University of Louisville \\ Louisville, KY
}

May 2015 
Copyright 2015 by Katie F. Leslie

All rights reserved 

THE INFLUENCE OF CHILD PHYSICAL ACTIVITY PROGRAMS ON PARENT PHYSICAL ACTIVITY IN A RURAL COMMUNITY

\author{
By \\ Katie F. Leslie \\ B.S., University of Kentucky, 2007 \\ M.S., University of Louisville, 2008 \\ A Dissertation Approved on
}

April 13, 2015

by the following Dissertation Committee:

Richard W. Wilson, DHSc, MPH, Dissertation Director

Kristi M. King, Ph.D., CHES

Patricia Gagne, Ph.D.

V. Faye Jones, M.D., Ph.D., M.S.P.H. 


\section{DEDICATION}

This dissertation is dedicated to my husband

Mr. Daniel Leslie

who provided the love, patience, and support for me to finish this journey. 


\section{ACKNOWLEDGEMENTS}

I would like to thank my dissertation committee, for their guidance and encouragement throughout this project. My advisor and committee chair, Dr. Richard Wilson, has been an invaluable resource and mentor to me throughout the entire doctoral program. Dr. Kristi King tirelessly worked with me on this project, sharing her community knowledge and contacts necessary to conduct this research. Dr. Patricia Gagne provided expertise for the design of this project and guided me as I encountered challenges. In addition to suggestions and guidance Dr. Faye Jones provided through her work with this project, her mentorship has afforded countless opportunities in my professional development.

I could not have completed this project without the backing of Mr. Aaron Greenwell and the staff of the Meade Activity Center. Thank you for all the work you do to improve the health of your community. I also want to thank the University of Louisville Commission on Diversity and Racial Equality (CODRE) and the School of Interdisciplinary and Graduate Studies for project funding through the Diversity Research Grant for Graduate Students.

I am grateful to my friends and fellow students who shared the highs and lows of this journey with me. I would also like to thank Dr. Prafula Sheth for providing advice, encouragement, and accountability. Finally, I would like to thank my family, my husband, Dan Leslie, my sister, Melissa Calabrese, and especially my parents, Jack and Donna Farmer, who taught me that education can take you anywhere. 


\title{
ABSTRACT \\ THE INFLUENCE OF CHILD PHYSICAL ACTIVITY PROGRAMS ON PARENT PHYSICAL ACTIVITY IN A RURAL COMMUNITY
}

\author{
Katie F. Leslie
}

April 13, 2015

Introduction: In 2008, a coalition of community leaders and parents sought to increase access to physical activity opportunities for residents of Meade County, a rural Kentucky

community. To date, the Meade Activity Center has implemented a variety of year-round programs conducted at borrowed spaces from local schools that have targeted children, utilizing the strategy to first engage children as a way to extend behavior change to other members of the community. This study assessed the influence of child participation in physical activity programs on parent physical activity, and determined potential methods of intervention to increase adult physical activity in a rural community.

Methods: Focus groups and individual interviews were conducted with a convenience sample of 21 parents of children who participated in the physical activity programs. Constructs from social cognitive theory and the social ecological model provided sensitizing concepts that were investigated during data collection. Data were audiorecorded, transcribed verbatim and analyzed using a grounded theoretical approach. Results: Findings revealed increased community awareness surrounding physical activity following program implementation. In addition to increased physical activity levels, 
children experienced social growth through program participation. Program effects in increasing child physical activity levels have somewhat "trickled-down" to influence physical activity in parents as well due to the close-knit, family-centered social environment specific to this community. Parents and children encouraged and motivated each other to be physically active, though younger children initiated joint physical activity more often than adolescents. Barriers to adult physical activity, including a lack of community spaces for families to be physically active together, were identified. Conclusions: These findings indicate a bidirectional influence between parent and child physical activity behaviors and the need for community recreational facilities where both children and adults can be physically active together. Study findings highlight the need for further research into the relationship between childhood physical activity interventions and parent health behaviors and outcomes. 


\section{TABLE OF CONTENTS}

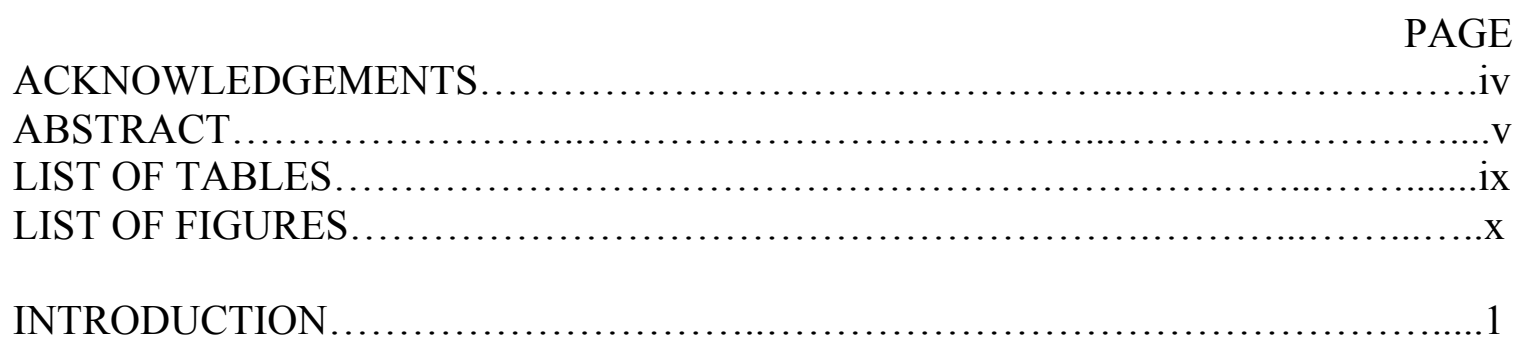

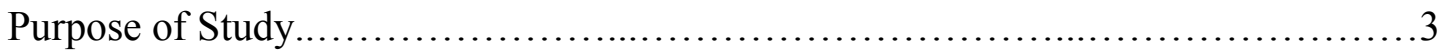

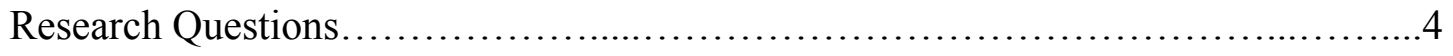

REVIEW OF LITERATURE.................................................. 8

Physical Activity........................................................

Child Influence on Parent Decision-Making.................................. 17

Theoretical Framework.................................................24

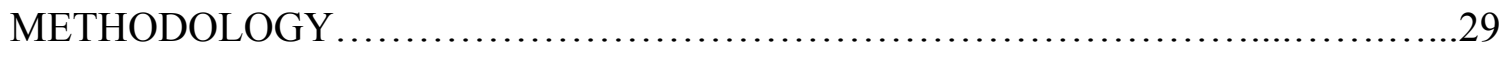

Recruitment Procedures................................................ 31

Data Collection...................................................... 34

Data Analysis........................................................41

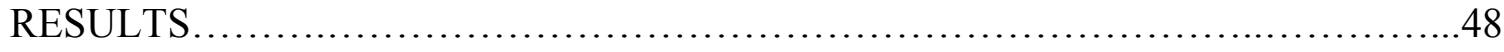

Participants...........................................................49

Family is Central to Community Identity..................................52

Increased Community Priority in Physical Activity............................55

Children Influence Parent Physical Activity..................................60 
Barriers to Parent Physical Activity.........................................65

DISCUSSION ............................................................. 72

Discussion of Research Questions......................................... 73

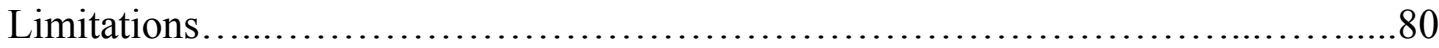

Conclusions and Implications.......................................... 82

REFERENCES........................................................ 87

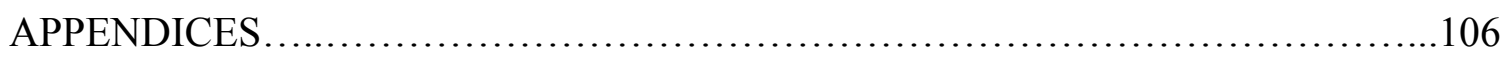

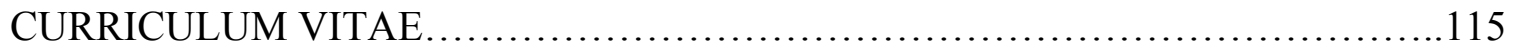




\section{LIST OF TABLES}

TABLE

PAGE

1. HP2020 Objectives to Increase Physical Activity Levels in Adults....................14

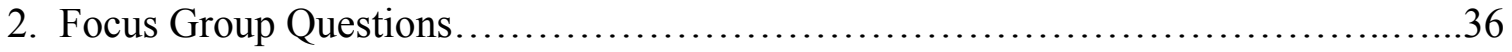

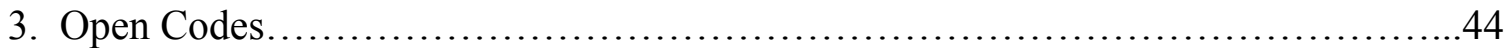

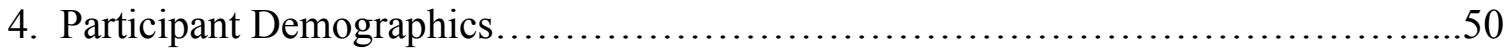

5. Child Characteristics and MAC Involvement.....................................51

6. Family Physical Activity .....................................................61 


\section{LIST OF FIGURES}

$\begin{array}{ll}\text { FIGURE } & \text { PAGE }\end{array}$

1. Theoretical Model of Parent Physical Activity...................................27 


\section{CHAPTER I \\ INTRODUCTION}

\section{Description of Problem}

Rural residency is an important predictor of health status, with rural populations experiencing numerous health disparities (Eberhardt \& Pamuk, 2004; Hartley, 2004). Rural areas also have higher rates of poverty and lower income levels than urban and suburban areas (Economic Research Service, 2010). In addition to rural residency, county-level poverty and per capita income are independent predictors of individual disease morbidity (Auchincloss \& Hadden, 2002).

Nationally, adults living in rural areas are more likely to be obese and physically inactive (Befort, Nazir, \& Perri, 2012; Parks, Housemann, \& Brownson, 2003; Patterson, Moore, Probst, \& Shinogle, 2004). Adults living in the rural South are significantly more likely to be physically inactive than their urban counterparts, even when controlling for socio-demographic variables (Martin et al., 2005). Monetary costs and geographic distance to physical activity facilities and programming within rural communities create additional barriers to adults engaging in these health behaviors (Huston, Evenson, Bors, \& Gizlice, 2003; Powell, Slater, Chaloupka, \& Harper, 2006).

\section{Background on Community}

Located in the north central portion of Kentucky, rural Meade County has an estimated population of approximately 29,237 residents (United States Census Bureau, 
2014). The adult population within this community demonstrates high rates for a number of poor health behaviors including a 37\% smoking rate, $36 \%$ obesity rate, and $30 \%$ physical inactivity rate (Robert Wood Johnson Foundation, 2014). In addition, this population is economically disadvantaged, with a per capita income of only $\$ 20,384$, $15.7 \%$ living below the poverty level, and a $10.1 \%$ unemployment rate (Robert Wood Johnson Foundation, 2014; United States Census Bureau, 2014). Only 12\% of Meade residents over age 25 hold a bachelor's degree, compared with the state rate of $21 \%$ (United States Census Bureau, 2014). Both independently and collectively, these social determinants of health place Meade residents at an increased risk for adverse health outcomes (Auchincloss \& Hadden, 2002).

In 2008, community leaders sought to increase access to recreational facilities, opportunities for physical activity, and health-related programming within Meade County, which were non-existent at the time. Addressing these needs became the primary goal for these community members (and the later formed coalition) and they formed the Meade Activity Center (MAC) during the same year. The focus of MAC is to create physical activity opportunities and venues that will address the gaps in availability and access to services due to income disparity at the individual and county levels. The MAC's goal is to open a fully operational activity center to be available on a sliding scale to all community members, so that they may live physically active lives.

Thus far, the main focus of the MAC coalition has been to develop programming centered on physical activity opportunities for community children. This was an intentional decision as one coalition member stated, "the way to get the adults there is to get the kids there...people are hungry to have things for their kids to do, and while we 
have them we can try to teach them better nutrition and to be physically active." Though no physical center exists, numerous programs have been implemented in borrowed locations throughout the community including schools, churches, and land donated to MAC.

Since July 2011, Dr. Kristi King, a member of this dissertation committee, has worked with the MAC in developing, implementing, and evaluating these programs. As a result, Dr. King is well respected in the Meade County community, and closely connected to the efforts of the MAC. To date, nearly 800 children have taken part in at least one of the physical activity programs. Children who participated in MAC programs have demonstrated improved health behaviors and outcomes (King \& Rice, 2014). With the success of the programming for children, the MAC is beginning to offer programming for adults as well. As these new programs are implemented, it is important to assess the efficacy of the MAC coalition's strategy to first engage community children in physical activity programming, as a way to extend the program's reach into the broader community.

\section{Purpose of Study}

As the literature review will demonstrate, there are only a small number of evidence-based strategies to increase adult physical activity at the community level (Kahn et al., 2002; Task Force on Community Preventive Services, 2002). Compared to other approaches, community-wide adult group-based interventions appear to be most effective in increasing physical activity in socio-economically disadvantaged communities (C. L. Cleland, Tully, Kee, \& Cupples, 2012; V. Cleland, Granados, Crawford, Winzenberg, \& Ball, 2013). However, the majority of these approaches have 
not been tested in rural settings, and may not be applicable to rural populations (Casey et al., 2008; C. L. Cleland et al., 2012).

Parental influence on child health behaviors, including physical activity, is well documented (Bauer, Nelson, Boutelle, \& Neumark-Sztainer, 2008; McMinn et al., 2011; Zecevic, Tremblay, Lovsin, \& Michel, 2010). Consumer behavior and marketing literature clearly demonstrates that children often play the role of change agents within the family structure and influence purchasing behaviors (Jenkins, 1979; Shoham \& Dalakas, 2005; Swinyard \& Sim, 1987; Wilson \& Wood, 2004). However, in current health promotion literature, bidirectional associations between parents and children in health behaviors are seldom considered and need further exploration (Craig, Cameron, \& Tudor-Locke, 2013; Sallis \& Nader, 1998).

The purpose of the current study is to assess the influence of child participation in physical activity programs on parent physical activity health behaviors within this rural community. This study will contribute to the dearth of literature regarding modeling and bidirectional associations between family members in health behaviors. Ultimately, this study may inform other community-based physical activity interventions in rural, lowincome populations.

\section{Research Questions}

This descriptive study utilized a qualitative research methodology to explore the influence of child participation in physical activity programs on parent physical activity health behaviors in a rural community. This was achieved through semi-structured focus groups and individual interviews with parents of children who were participants in any of the MAC physical activity programs. Core questions for the focus groups centered on 
parent and child physical activity health behaviors rooted in theoretical constructs from the social ecological model and social cognitive theory (Bandura, 1989; McLeroy, Bibeau, Steckler, \& Glanz, 1988). An analytic inductive method designed to lead to grounded theory, as prescribed by Charmaz (2006), was selected to guide the methodological approach to data collection and analysis. The review of literature, along with constructs from social cognitive theory and the social ecological model, did provide sensitizing concepts, or points of reference, that were investigated in this study (Blumer, 1969). However, the researchers remained open to concepts, patterns, and trends that emerged from the data, following grounded theory. The following research questions guided this exploratory study:

Research Question 1: Do parents believe the MAC project has influenced their children's physical activity behaviors?

Research Question 2: Has the MAC project influenced adult physical activity behaviors?

Research Question 3: What is the influence on parent physical activity resulting from child participation in MAC physical activity programs?

Research Question 4: What are the barriers and enabling factors to participation in adult MAC physical activity programs?

\section{Delimitations}

This study was delimited to parents of children who had participated in MAC activities. To be considered for enrollment into the focus groups or individual interviews, 
the participants had to reside in Meade County, Kentucky, participated in at least one MAC program, volunteered for the study, and completed the consent process to be interviewed. Current or past members the MAC coalition or staff were excluded from the study.

\section{Limitations}

This study utilized a community-engaged research approach, which is "the process of working collaboratively with and through groups of people affiliated by geographic proximity, special interest, or similar situations to address issues affecting the well-being of those people. It is a powerful vehicle for bringing about environmental and behavioral changes that will improve the health of the community and its members" (Centers for Disease Control and Prevention, 1997, p. 9). The focus of this dissertation was an extension of a multi-year community-based physical activity health promotion intervention, in which other researchers from the University of Louisville have worked in partnership with and in the community. As this dissertation was designed specifically for the community of Meade County, and researchers from the University of Louisville were engaged with the community for an extended period of time, generalizability to other communities may be limited.

Another possible limitation is that enrollment relied on participants volunteering for the study by responding to recruitment communications sent by the MAC Executive Director, or posted community fliers, or through recruitment conversations with the researcher at MAC programming. These individuals may be more involved with the MAC and/or more physically active in general, than others eligible for the study. 
Additionally, study results were based on self-reported data obtained during focus groups and individual interviews, not actual observed physical activity behaviors.

\section{Operational Definitions}

The following operational definitions are provided to clarify the manner in which these terms will be used in this study.

Behavior Modeling: the adoption of a behavior by an individual after observing the behavior from another.

Bidirectional Influence: the co-occurrence of both directions of influence between one player and another within a social system. For example, a child's parents have an influence on his or her beliefs and behaviors, but the child can also influence the parents' beliefs and behaviors.

Community: a group of people who are linked by social ties and share common perspectives or interests and may also share a geographic location (Centers for Disease Control and Prevention, 1997). In this study “community" will refer to Meade County.

Parent: refers to biological parent, legal parent, stepparent, and/or other qualifying adult living in the household with and responsible for the care of a child.

Physical Activity: bodily movement that enhances health (U. S.

Department of Health and Human Services, 2008). 


\section{CHAPTER II}

\section{REVIEW OF THE LITERATURE}

\section{Introduction}

The purpose of this study was to assess the influence of child participation in physical activity programs on parent physical activity health behaviors in a rural community. Family units are an important and influential interpersonal social system. Unfortunately, little is known about child influence on parent health decisions and behaviors. This gap in knowledge may limit the ability to design effective health promotion interventions that engage children as a way to extend behavior change to other members of the family. The present study will contribute to the dearth of literature regarding the bidirectional interpersonal influences between family members in health behaviors.

A literature review was conducted in order to gain an understanding of the current state of knowledge pertaining to physical activity in adults, child influences on parental behaviors, and community approaches to increase physical activity in adults. Searches within multiple online bibliographic databases were conducted through PubMed, Google Scholar, and EBSCO. An initial search was conducted in PubMed through combinations of the following search terms and phrases: "physical activity," "exercise," "health behavior," "behavior," “child," “parent," "adult," "family," "influence," "determinants," "modeling," "reciprocal," "bidirectional," "community based," "community," 
"ecological," and "rural." Subsequent searches through Google Scholar and EBSCO were conducted using the same search terms to the point of saturation, and duplicate studies were removed.

Practical screening criteria were applied to search results to limit the review to publications written in English. Titles and abstracts of the collected articles were closely reviewed to further screen for relevancy. Inappropriate articles were discarded, and full manuscripts of seemingly applicable articles were reviewed. Hand searching measures were utilized to locate references within selected articles to assure the inclusion of all key publications. Systematic reviews and meta-analyses were given priority for concepts with larger evidence bases, while multiple methodological designs were considered for concepts with fewer publications. In addition to bibliographical databases, searches were performed within websites for relevant associations, organizations, and governments to determine supplementary epidemiological and other relevant data relating to physical activity.

\section{Physical Activity}

According to the U. S. Department of Health and Human Services (2008), physical activity generally refers to "bodily movement that enhances health" (p. 2). It is recommended that adults aged 18 to 64 perform at least 150 minutes a week of moderateintensity or 75 minutes a week of vigorous-intensity aerobic activity (U. S. Department of Health and Human Services, 2008). Examples of aerobic activity include running, brisk walking, hiking, bicycling, swimming, basketball, tennis, jumping rope, or gardening. Additional health benefits result from increasing to 300 minutes of moderate-intensity aerobic activity, or 150 minutes of vigorous-intensity physical activity (or combination of 
both) per week, and it is also recommended that adults do muscle-strengthening activities 2 or more days per week (U. S. Department of Health and Human Services, 2008).

\section{Associated Benefits of Physical Activity and Risks of Inactivity}

Physical inactivity is clearly a contributing factor to overweight and obesity. In combination, physical inactivity and obesity present numerous risks for adverse health outcomes and complications (Blair \& Brodney, 1999; National Institutes of Health, 1998). Independent of obesity, physical inactivity also increases risk for a number of adverse health conditions including type II diabetes, certain cancers, stroke, hypertension, cardiovascular disease, depressive disorders, and premature mortality (Lee et al., 2012). Furthermore, physical inactivity has been identified as the fourth leading risk factor for global mortality causing an estimated 3.2 million deaths per year (World Health Organization, 2010). Physical activity is an important factor in chronic disease prevention and management (Pate et al., 1995; U. S. Department of Health and Human Services, 1996, 2008). Regular physical activity can improve the health and quality of life for Americans of all ages (U. S. Department of Health and Human Services, 2008; U. S. Department of Health and Human Services Healthy People 2020, 2013).

Aside from the increased morbidity and mortality risks, the economic burden of physical inactivity in the U.S. is estimated to result in approximately $\$ 24$ billion per year in health care costs (Colditz, 1999). While this is a staggering number, this does not account for other non-medical societal costs of physical inactivity. High prevalence rates of physical inactivity in adults may further dampen local economies as industries and businesses looking for a healthy workforce may be reluctant to settle or stay there. Physically inactive and other unhealthy adults are unattractive to potential employers as 
they present higher rates of disability and absenteeism, and lower rates of productivity and presenteeism (Goetzel, Hawkins, Ozminkowski, \& Wang, 2003; Loeppke et al., 2007). Thus, the negative impact of physical inactivity on overall community health and well-being is far reaching.

\section{Epidemiology}

Although there is much evidence in regards to the benefits of being physically active, more than $80 \%$ of U.S. adults fall short in meeting the recommended guidelines for aerobic physical activity and muscle-strengthening activity (U. S. Department of Health and Human Services Healthy People 2020, 2013). Additionally, there are significant differences in physical activity levels among demographic subgroups. Compared to other racial and ethnic groups, Non-Hispanic white adults are more likely to meet the recommended physical activity guidelines (Schoenborn, Adams, \& Peregoy, 2013). Adult men are more likely than women to meet the recommended physical activity guidelines and physical activity levels in adults decline with age (Schoenborn et al., 2013). In addition, adult physical activity levels are positively associated with both educational attainment and family income levels (Schoenborn et al., 2013)

Nationally, rural adults are least likely to be physically active (Parks et al., 2003;

Patterson et al., 2004; Schoenborn et al., 2013). Additionally, adults living in the rural South are significantly more likely to be physically inactive than their urban counterparts, even when controlling for socio-demographic variables (Martin et al., 2005; Schoenborn et al., 2013). Ninety-eight of Kentucky's counties are classified as rural/non-metropolitan and over $41 \%$ of Kentucky residents reside in rural areas, almost twice the national average (United States Department of Agriculture Economic Research Service, 2011). 
According to the 2011 Behavioral Risk Factor Surveillance System, 29.3\% of adults in Kentucky reported that during the past month, they had not participated in any physical activity (Centers for Disease Control and Prevention, 2011).

\section{Barriers and Enabling Factors}

Common barriers to adults engaging in physical activity include: lack of time, low self-efficacy, lack of skill, lack of motivation, lack of energy, fear of injury, lack of social support, and lack of resources (Rhodes \& Dickau, 2013; Sallis \& Hovell, 1990; Sallis, Hovell, \& Hofstetter, 1992). Individuals are more likely to adopt physical activity behaviors if it is easily accessible and enjoyable (Hillsdon, Thorogood, Anstiss, \& Morris, 1995). In accordance with ecological models, environmental barriers to physical activity, including lack of access to safe areas, facilities, and programming where one can be physically active, may further exacerbate rural disparities in physical activity levels (Calise, Heeren, DeJong, Dumith, \& Kohl, 2013; Casey et al., 2008; Huston et al., 2003;

Lovasi, Hutson, Guerra, \& Neckerman, 2009; McCormack \& Shiell, 2011; Powell et al., 2006). In addition to safe and accessible spaces, the presence of other enabling factors may encourage physical activity in adults.

Parenthood itself may also be a barrier to physical activity in adults (BellowsRiecken \& Rhodes, 2008). Declines in physical activity levels are often seen as adults shift into roles as parents (Albright, Maddock, \& Nigg, 2006; Hull et al., 2010; McIntyre \& Rhodes, 2009; Rhodes et al., 2014). Balancing work responsibilities, household demands, and childcare may lead to scheduling constraints and reduced time for parents to participate in physical activity (Mailey, Huberty, Dinkel, \& McAuley, 2014). Instrumental support such as available child care to allow for time for physical activity 
may increase participation (Hamilton \& White, 2010). As parents with dependent children are comparatively more inactive than non-parent adults, Bellows-Riecken and Rhodes (2008) highlighted the need for further investigation of interventions to increase physical activity levels in parents with dependent children, focused within a social ecological framework.

\section{Evidence-Based Approaches to Increase Physical Activity in Adults}

Increasing physical activity in all age groups is a top public health priority and a leading health indicator in Healthy People 2020 (U. S. Department of Health and Human Services Healthy People 2020, 2013). Goals to improve physical activity in adults are summarized in Table 1. Interventions to increase physical activity in adult populations have been designed to target adults within different levels (individual, interpersonal, community, and policy) of influences and in a variety of settings. Despite a multitude of studies investigating interventions to increase physical activity in adults, there remain a small number of evidence-based strategies to address this issue. 
Table 1

Selected Healthy People 2020 Objectives to Increase Physical Activity Levels in Adults

Percentage of Total U.S. Population

Objective

Baseline

2020 Target

Reduce the proportion of adults who engage

$36.2 \%$

$32.6 \%$

in no leisure-time physical activity

Increase the proportion of adults who

$43.5 \%$

$47.9 \%$

engage in aerobic physical activity of at

least moderate intensity for at least 150

minutes/week, or 75 minutes/week of

vigorous intensity, or an equivalent

combination

Increase the proportion of adults who

engage in aerobic physical activity of at

$28.4 \%$

$31.3 \%$

least moderate intensity for more than 300

minutes/week, or more than 150

minutes/week of vigorous intensity, or an

equivalent combination

Increase the proportion of adults who

$21.9 \%$

$24.1 \%$

perform muscle-strengthening activities on

2 or more days of the week

Increase the proportion of adults who meet

the objectives for aerobic physical activity

and for muscle-strengthening activity

(U. S. Department of Health and Human Services Healthy People 2020, 2013)

Many health promotion programs guided by behavioral theories are targeted to

change an individual's health behaviors based on their readiness to change or specific

interests. Communications between patients and providers can have a significant

influence on certain patient health behaviors. However, within clinical settings, the U.S.

Preventive Services Task Forces found only a small benefit in behavioral counseling to

promote physical activity, and recommended that primary care clinicians selectively 
provide this service to individual patients (Buckler \& Servies, 2013; Moyer \& Force, 2012). Additionally, physical activity behavioral changes resulting from these interventions appear to be short-lived (Eakin, Glasgow, \& Riley, 2000). Individually adapted physical activity health behavior change programs are also efficacious in increasing adult physical activity levels (Kahn et al., 2002). However, public health interventions at the individual level appear to have the least impact on health outcomes at the population level (Frieden, 2010).

Interpersonal approaches to increasing physical activity health behaviors in adults are rooted in the behavioral constructs of building social networks and increasing social support (Centers for Disease Control and Prevention, 2001; Kahn et al., 2002). Social support interventions in community settings were found to be effective in increasing physical activity (Kahn et al., 2002; Task Force on Community Preventive Services, 2002). These strategies include setting up "buddy systems" with peers or exercise groups for physical activity through pre-existing social groups, outside of the family (Centers for Disease Control and Prevention, 2001; Kahn et al., 2002).

Although families are an important social group, there is insufficient evidence to determine the effectiveness of family-based social support physical activity interventions due to inconsistent findings in available studies (Kahn et al., 2002). These strategies include interventions that are targeted to children and families, and are generally implemented through school systems (Centers for Disease Control and Prevention, 2001; Kahn et al., 2002). The effectiveness of these studies is difficult to evaluate collectively as there are often varying and multiple arms of these interventions. Outcomes of each intervention component are difficult to measure and compare across similar studies. 
Community-level interventions utilizing multicomponent approaches including large-scale health communication campaigns through local radio, television, newspaper, and other media channels have demonstrated success in increasing physical activity levels (Centers for Disease Control and Prevention, 2001). Additional approaches aimed at changing the local environment by creating or increasing access to places for physical activity are highly effective strategies to increase physical activity and reduce obesity in communities (Task Force on Community Preventive Services, 2002). Community-wide interventions are also cost-effective (Roux et al., 2008). Compared to other approaches, community-wide adult group-based interventions appear to be most effective in increasing physical activity in socio-economically disadvantaged communities (C. L. Cleland et al., 2012; V. Cleland et al., 2013). However, the evidence of best approaches to increase physical activity in disadvantaged populations remains limited (Everson-Hock et al., 2013).

Overall, there is limited evidence in regards to effective behavioral, social, and environmental health promotion interventions to increase physical activity in adults. Specifically, more research is needed to determine the effectiveness of family-based interventions in community settings. Even with proven approaches to increase physical activity, difficulty can arise with implementation and adaptation of interventions (Lattimore et al., 2010). In addition, much of the evidence of these approaches comes from studies conducted in urban and suburban populations near academic research centers. Thus, these strategies may not translate when implemented in rural settings given the different environmental, cultural, and social norms (Casey et al., 2008; C. L. Cleland 
et al., 2012). More research is needed to identify potential strategies and examine the efficacy of adult physical activity interventions, particularly in rural populations.

\section{Child Influence on Parent Decision-Making}

Family units serve as the major social institution in most societies, and are systematic sources of interpersonal influence among individual actors (Cook, 2001). The commonly held view is that parents teach children their knowledge, values, and beliefs, and children model after parental behaviors. However, behavioral influences within family systems are not always top-down and unidirectional, with children being passive recipients of parental influence. Patterns of reciprocity of influence exist throughout family relationships, including bidirectional decision and behavioral influences within parent-child dyads (Cook, 2001; De Mol \& Buysse, 2008). Accordingly, these family dynamics are important determinants of health behavior patterns among family members (Sallis \& Nader, 1998).

Disciplines outside of health promotion have long targeted children as a proxy to reach and influence the behavior of their parents. Consumer behavior and marketing literature clearly demonstrates that children often play the role of change agents within the family structure and influence purchasing behaviors (Jenkins, 1979; Shoham \& Dalakas, 2005; Swinyard \& Sim, 1987; Wilson \& Wood, 2004). Additionally, children are often the first to adopt new technologies within households and influence and instruct their parents in the utilization of these innovations (Belch, Krentler, \& Willis-Flurry, 2005; Brown \& Venkatesh, 2005; Correa, 2014; Götze, Prange, \& Uhrovska, 2009). While mainstream marketing campaigns have used children as a conduit to reach parents 
for many years, health promotion interventions have largely failed to capitalize on this channel of influence.

\section{Parent-Child Physical Activity Correlates}

Family aggregation, that is, similarities in health variables among family members, has been identified with systematic evidence for a number of preventive health behaviors (Leonardi-Bee, Jere, \& Britton, 2011; Pearson, Biddle, \& Gorely, 2009; Sallis \& Nader, 1998). However, current empirical data on family influence on preventive health behaviors remains largely one-sided. The majority of public health studies examining parent-child preventive health behaviors are framed to examine parental influence on child health behaviors and outcomes. Numerous studies have examined the parent-child relationship in regards to physical activity health behaviors. In fact, parental influence on physical activity is one of the most frequently studied social variables in the literature examining correlates of child and adolescent physical activity (Sallis, Prochaska, \& Taylor, 2000).

Child physical activity is both directly and indirectly associated with physical activity levels of parents (Craig et al., 2013; Dowda et al., 2011; Isgor, Powell, \& Wang, 2013). Children model parent physical activity behaviors, as child perceptions of parent physical activity predicts their own physical activity levels (Madsen, McCulloch, \& Crawford, 2009; Moore et al., 1991). Parental social support and encouragement of physical activity positively influences physical activity health behaviors in children (Bauer et al., 2008; Hennessy, Hughes, Goldberg, Hyatt, \& Economos, 2010; Ornelas, Perreira, \& Ayala, 2007; Sallis et al., 2000; Trost et al., 2003; Zecevic et al., 2010). Increasing physical activity in parents may be an effective way to promote physical 
activity health behaviors in children (Bauer, Neumark-Sztainer, Fulkerson, Hannan, \& Story, 2011; Timperio et al., 2013). However, the level of parental influence appears to change over time, decreasing as children age (Alderman, Benham-Deal, \& Jenkins, 2010)

Demographics such as race, ethnicity, parent education levels, parent and child gender, and number of children in the home also contribute to differences in the level of parent-child influence (Anderson, Hughes, \& Fuemmeler, 2009; Bauer et al., 2008; Hennessy et al., 2010; McMinn et al., 2011). Strength of behavioral influence also appears to differ across parent-child dyads (for example, mother-daughter, mother-son, father-daughter, father-son) (Craig et al., 2013; DiLorenzo, Stucky-Ropp, Vander Wal, \& Gotham, 1998). Financial constraints among lower SES families may decrease family support for and participation in structured physical activity programs (Brockman et al., 2009).

Based on the above literature, physical activity in children is related to that of their parents. However, current literature seldom considers bidirectional associations. Craig et al. (2013) called for further studies to evaluate the direction of this relationship, confirm the magnitude of influence, and determine mediating and moderating mechanisms of these influences. In addition, the current literature does not employ consistent definitions and measures of physical activity within studies, which limits comparability of results.

\section{Child-Parent Influence in Health Behavior}

Using children as a proxy to reach parents is not a new strategy in public health, particularly in regards to health education and health communication. By way of school systems, children are an accessible audience and are often utilized as a logical channel for 
health education campaigns. Much public health education is aimed at children with the rationale that children influence the attitudes of their parents, who will consequently change their behavior. For example, Mitchell, Haynes, Hall, Choong, and Oven (2008), described the role of children as risk communicators in the field of disaster preparedness, and present case studies in which youth were effective communicators of disaster risk and had the power to persuade their families and communities to act. In current health promotion literature, however, empirical evidence to substantiate this intuitive strategy is very limited, as few studies have measured bidirectional influences between parents and children in health behaviors.

In the 1970s, the National Highway Traffic Safety Administration (NHTSA) implemented a seatbelt education program for elementary school children (this was before the advent of shoulder-harnesses and the wide spread adoption of seatbelt laws) (National Highway Traffic Safety Administration, 1972). The program was designed to increase lap belt usages among elementary school children (students enrolled in Kindergarten through seventh grade) during a one-month period in which each child received an approximate total of three hours of education. As a possible "spin-off" it was hoped that the children would influence their parents and other family members to wear safety belts. While the majority of students reported telling their parents about the importance of seatbelts, this observational study found a statistically significant increase in seatbelt use among children who had received the education, but no substantial effect was seen in parent seatbelt usages. However, this was a small-scale pilot with direct observation (visually observing seatbelt usage at community parking lots), within a very short time period. 
Schuck, Otten, Engels, Barker, and Kleinjan (2012), investigated longitudinal associations and bidirectional influences between family members in smoking behavior. In this study of 426 Dutch family units (each family consisted of mother, father, and two adolescent children), associations in smoking behaviors were assessed annually over a 5year period using a cross-lagged model in structural equation modeling. Cross-lagged models collect data multiple times on the same individuals over time to provide evidence regarding the strength and causality between variables (i.e. if child smoking intensity is the cause of parent smoking intensity, then child smoking intensity at Time 1 should be related to parent smoking intensity at Time 2). Measures included smoking intensity as indicted by the average number of cigarettes smoked per week. The results of this study identified partner effects, sibling effects, and parent-child effects on smoking intensity, consistent with previous findings in the literature (Etcheverry \& Agnew, 2008; LeonardiBee et al., 2011). However, the results of Schuck et al. (2012) also identified several child-parent effects, as the smoking intensity of older adolescent children predicted the smoking intensity of fathers and the smoking intensity of the younger adolescent children predicted the smoking intensity of the mothers. This study demonstrates bidirectional influences between parents and children in smoking behavior, and reveals that changes in one family member's health behavior, including that of a child, may have a contagion effect on the same health behavior within the family, including parents, across time.

In a health communications study using both cross-sectional and longitudinal data relating to dietary behaviors, Rimal and Flora (1998) found that family members were not only influenced by a health communication campaign, but also by the interpersonal communications between family members sparked by the campaign itself. They suggest 
that public health campaigns can be more effective if they conceptualize both children and adults as potential sources of influence. Although Rimal and Flora (1998) documented the reciprocal influences of family members, the authors called for further research into the dynamics of family influence, as most research has utilized the parentchild "gatekeeper" model of top-down influence.

Heim, Bauer, Stang, and Ireland (2011) examined changes in the home food environment resulting from a 12-week YMCA fruit and vegetable pilot program targeting grade school children. A convenience sample of 83 parents completed pre-and post-tests assessing the frequency of their child asking for fruits and vegetables at home, home availability and accessibility of fruits and vegetables, and parent fruit and vegetable consumption. Analysis revealed a significant increase in the frequency of the child asking for fruits and vegetables $(\mathrm{p}<.01)$ as well as parental consumption of fruits and vegetables $(\mathrm{p}<.01)$. Results from this pilot study demonstrate the influence children may have on their parents in food purchasing and consumption behaviors. However, the small sample size and lack of control group limit the strength of this study.

In a community-based participatory research study, Coffield, Nihiser, Sherry, and Economos (2015) assessed changes in parent body mass index (BMI) resulting from a child-targeted obesity intervention. Shape up Somerville was a 2-year, school-based program designed to increase physical activity levels and dietary habits of elementary school children enrolled in 10 elementary schools in Somerville, Massachusetts. In addition to measures conducted on the targeted population (the children), the researchers also assessed changes in BMI of 122 Somerville parents through pre- and postintervention questionnaires. Questionnaires were also completed by 356 elementary 
school parents that had children in 20 elementary schools in communities outside the Somerville media market, who served as the control group. The intervention was associated with decreased BMIs among Somerville parents, who experienced a 0.411 point reduction compared with control parents. Results from this study suggest that the benefits of child-targeted interventions my go beyond the intended audience and spill over to positively influence the health behaviors of parents and other family and community members.

\section{Need for Future Research to Assess Child Influence on Parent PA}

Public health scholars have called for theory-driven studies pertaining to the family determinants of preventive health behaviors, and have highlighted the potential for interventions targeting children to benefit adults in the family as well (Gruber \& Haldeman, 2009; Sallis \& Nader, 1998). However, few health promotion studies have been conducted to further develop the current state of knowledge regarding family influence. In health behavior research, such as that of physical activity, measurement of bidirectional causal influences is complex (Bauman, Sallis, Dzewaltowski, \& Owen, 2002). The majority of the literature that examined physical activity behavior influences within families was cross-sectional, correlational in nature, with variables measured outside of controlled interventions, which is insufficient for making implications regarding behavioral influence (in any direction). Moreover, it was the assumption that all associations in physical activity health behaviors were top-down, from parent to child.

Cross-lagged models, as used by Schuck et al. (2012) to assess influences between family members in smoking behavior, is a popular design to measure bidirectional influences in other fields such as parenting and family studies research. 
However, mechanisms of influence of health behaviors within families have not been systematically identified and measured (Sallis \& Nader, 1998). Large gaps in the literature still remain and the need for further research into bidirectional interpersonal influences between family members is great. In measuring social influence in health promotion, "preliminary research using individual open-ended interviews or focus groups may be helpful for evaluating the applicability of proposed measures and suggesting new facets or dimensions that are not precisely represented in existing scales" (Willis, Ainette, \& Walker, 2008). Thus, descriptive studies are needed to establish predictors and enabling factors regarding the influence of child physical activity levels on parent physical activity health behaviors.

\section{Theoretical Framework}

In the field of health promotion, numerous theories and models identify psychological, social, and environmental influences on health behaviors. Core principles and constructs found in the Social Ecological Model as well as Social Cognitive Theory were employed as sensitizing concepts to guide the development of the semi-structured interview guide used during data collection.

\section{Social Cognitive Theory}

Social Cognitive Theory (SCT) provides a theoretical account of environmental influences in individual behavior, and asserts that health behavior is the result of reciprocal relationships among the environment, personal factors, and attributes of the behavior itself (Bandura, 1986). The SCT construct of observational learning incorporates behavioral acquisition or modeling of the behaviors and actions of others (Bandura, 1997). Within the context of SCT and child development, Bandura (1989) 
presented bidirectional modeling relating to how parents and children influence each other.

However, studies in health promotion have been one-sided, focused on the influence that parents have on their children, rather than how parents and children influence each other. In order to facilitate behavioral change, the individual's (the observer of the behavior) environment, both physical and social, must also be supportive of the modeled behavior (McAlister, Perry, \& Parcel, 2008). In the present case, the environmental factors would be access to physical activity opportunities for parents, as well as familial and social structures.

\section{Social Ecological Model}

Ecological models are also commonly used in health promotion studies, particularly those in community settings. The Social Ecological Model (SEM) asserts that behavior affects and is affected by multiple levels of influence, and that individual behavior shapes, and is shaped by, the social environment (McLeroy et al., 1988; Stokols, 1992, 1996). The SEM is a systems model with multiple bands of influence. Within this model, the interpersonal processes and groups providing identity and support, including familial relationships, are accounted for at the interpersonal level of influence (McLeroy et al., 1988).

At the core of the SEM model is the individual (intrapersonal level), surrounded by bands of influence representing the interpersonal, organizational, community, and policy levels. SEM models are well-suited for community physical activity interventions, as physical activity takes place at specific locations, such as community centers, parks, walking/jogging paths, and other fitness venues (Sallis et al., 2006). Numerous studies 
have employed an ecological framework to describe the influences of child physical activity health behaviors (Kellou, Sandalinas, Copin, \& Simon, 2014; Langille \& Rodgers, 2010; Mehtala, Saakslahti, Inkinen, \& Poskiparta, 2014). In these cases, the child was the individual with parents and family members placed within the interpersonal level of influence.

\section{Adapted Model}

According to Sallis et al. (2006), "Psychosocial models can be integrated into ecological frameworks to provide specific hypotheses for a given level, such as intrapersonal" (p. 299). This study integrates the SCT concept of modeling within an ecological model as a framework for parent physical activity behaviors. As demonstrated

in Figure 1, the model has been adapted to place the parent as the individual and the child as part of the interpersonal level of influence. 


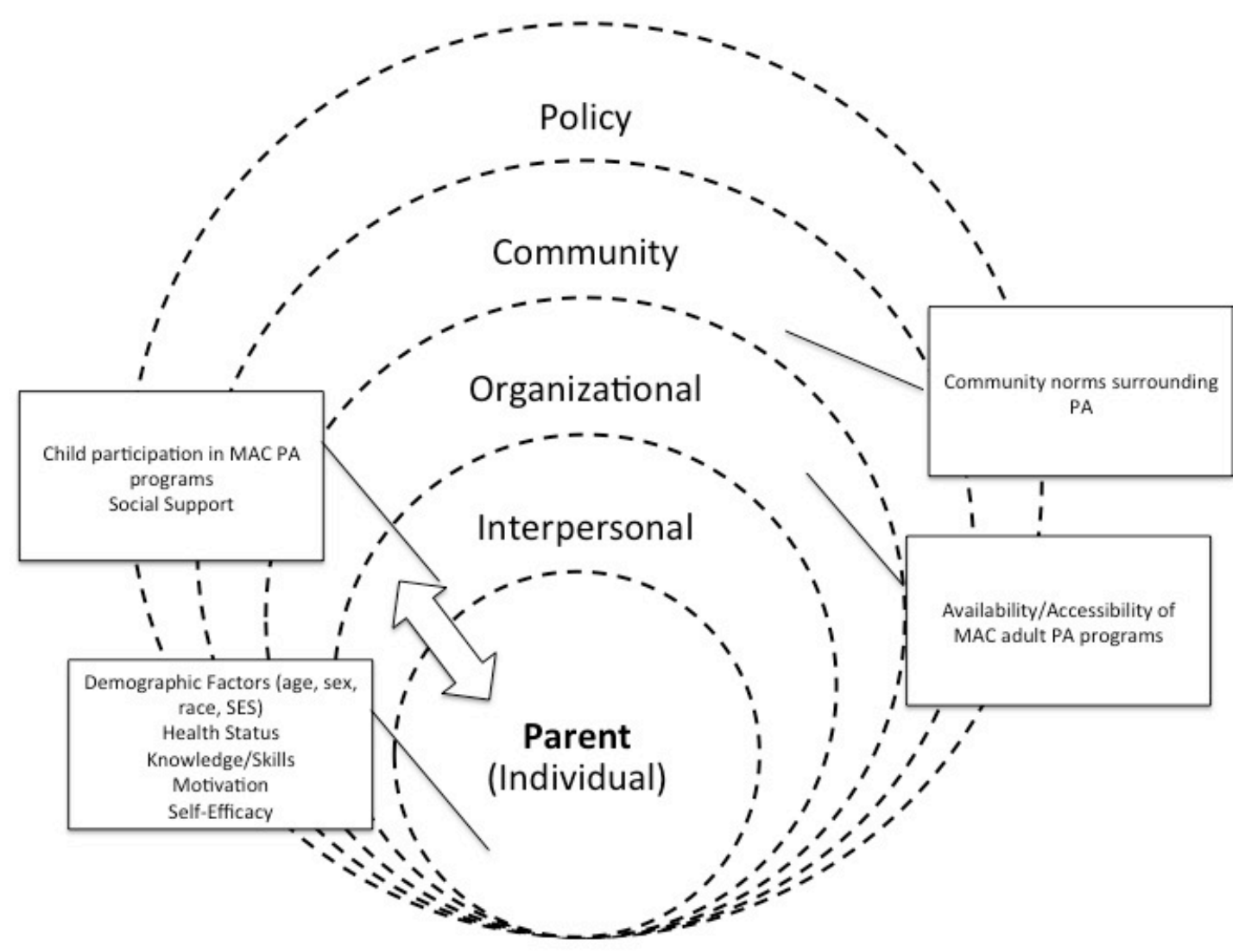

Figure 1. Theoretical model of parent physical activity.

\section{Summary}

This review of studies pertaining to adult physical activity and interpersonal influences between family members in health behaviors identified a large gap in the literature and opportunities for more research. While there is existing research on correlations between parent and child physical activity health behaviors, the current body of literature fails to account for bidirectional behavioral influences. It is conceivable that parents may be influenced by their children's physical activity health behaviors, as the literature demonstrates children influence parent behaviors and decision-making, a 
phenomenon that has been documented with other preventive health behaviors. It is not sufficient to assume a top-down unidirectional model of physical activity behavioral influence from parent to child. In addition, there is a need to examine community-based strategies to increase adult physical activity in rural populations. Given the high levels of physical inactivity and the limited available health promotion resources to address this issue, it is a matter of serious concern that there are virtually no studies in the literature that examine this potential channel of influence.

This project extends the available literature examining the influence of child participation in physical activity programs on parent physical activity health behaviors. This exploratory study seeks to identify mechanisms of bidirectional influence including contributing predictors and enabling factors. Findings from this study may aid in future research to develop an instrument to clearly identify, assess, and measure these channels of influence. This study also adds to the literature regarding ecological approaches to increase physical activity in rural communities. Chapter 3 follows and describes the methodology used for the study. 


\section{CHAPTER III \\ METHODOLOGY}

\section{Introduction}

This study employed a qualitative descriptive research design using an analytic inductive method of data collection and analysis to explore the influence of child physical activity on parent physical activity health behaviors in a rural community. This was achieved through conducting focus groups and individual interviews with parents of children who were participants in Meade Activity Center (MAC) physical activity programs. The study design and data collection methods were guided by a grounded theoretical approach described in this chapter.

\section{Qualitative Research Methods}

As described in chapter 2, there is a dearth of studies concerning child influence on parent physical activity behaviors. Exploratory studies are needed to identify mechanisms of bidirectional influence including contributing predictors and enabling factors. Topics that need to be explored, and examined in detail, and conducted in community settings fit well within the qualitative research paradigm (Creswell, 2013).

A focus group design was originally chosen as the only form of data to be gathered for the study. Morgan (1997) defines focus groups as "a research technique that collects data through group interaction on a topic determined by the researcher" (p. 6). Although the aim of a focus group is to emphasize actual behaviors and experiences 
while avoiding opinions, a major limitation is that behaviors are self-reported and not directly observed. However, as this study focused specifically on the topics of the MAC and physical activity behaviors, collecting data through participant observation would have been far too broad and time consuming. While somewhat logistically challenging to organize and schedule groups of people to come together at one time, compared to individual interviews, focus groups allow for the collection of large amounts of data on a topic in a shorter amount of time, while group discussions "provide direct evidence about similarities and differences in the participants' opinions and experiences, as opposed to reaching such conclusions from post hoc analyses of separate statements from each interviewee" (p. 10). These group interactions provide additional insight into behaviors, motivations, and attitudes (Krueger \& Casey, 2009).

While the intention was to only conduct focus group interviews, recruitment and scheduling challenges resulted in the inclusion of individual interviews. While more time consuming to conduct and analyze than focus groups interviews, individual interviews allow for greater exploration into topics, and participants may be more candid and willing to voice their experiences with topics than they would typically express in a group setting (Gillham, 2000). Ultimately, employing two methods of collecting qualitative data allowed for both in depth exploration of experiences at the individual level as well as idea generation and group interplay surrounding experiences through group discussions.

\section{Grounded Theory Approach}

In qualitative research, "grounded theory methods consist of systematic, yet flexible guidelines for collecting and analyzing qualitative data to construct theories 'grounded' in the data themselves" (Charmaz, 2006, p. 2). The origins of grounded 
theory are rooted in sociologists Barney Glaser and Anselm Strauss' work in examining the experience of dying hospital patients (Glaser \& Strauss, 1965, 1967, 1968). Prior to this time, qualitative research was theory and hypotheses driven with a priori assumptions. Grounded theory consists of three basic elements: concepts (basic themes), categories (groupings of concepts), and propositions (hypotheses) (Cottrell, McKenzie, \& James, 2010). In essence, grounded theory identifies patterns and themes, then builds concepts and connects them together into a theoretical explanation that accounts for the lived experiences of those studied (Charmaz, 2006).

A grounded theoretical methodology was selected for this study as it is a particularly useful methodological approach when current theories about a phenomenon are either inadequate or nonexistent (Creswell, 2013). This study seeks to explore the influence of child physical activity on parent physical activity behaviors in a rural community. A grounded theory approach can be used to develop a theory to explain this concept or provide a framework for further research, which aligns well with the aims of this study (Creswell, 2013).

\section{Recruitment Procedures}

In October 2014, participants were recruited for focus groups through informational flyers placed at MAC activity locations and through the MAC's existing database of nearly 800 children who have taken part in at least one of the physical activity programs. To be considered for enrollment into the focus groups, the following criteria must have been met:

1. Reside in Meade County

2. Have a child living in the home who participated in at least 1 MAC activity 
Current or past members of the MAC coalition or staff were excluded from the study. Only one adult per household was eligible to participate in the study.

In addition to posting recruitment flyers at MAC activities, the researcher worked closely with the MAC Executive Director, Aaron Greenwell, in recruiting parents to the study. Mr. Greenwell distributed recruitment emails to addresses in the MAC database requesting approximately 90 minutes of their time to participate in a focus group. Mr. Greenwell also included a voucher for savings on future MAC programs as an incentive for parents to participate. The recruitment email and flyer are provided in Appendices A and $\mathrm{B}$.

Recruitment emails and flyers instructed potential participants to call the researcher to screen for inclusion and determine availability to schedule for a focus group time. At this time, the researcher asked several screening questions (Are you a resident of Meade County? Has your child participated in any MAC program? Are you willing to participate in a research study? Has another adult in your household already participated in the study?).

Despite the prior relationship with Dr. Kristi King, who has worked with this community since 2011, and the endorsement of Aaron Greenwell, a key stakeholder and gatekeeper, response to these initial recruitment efforts was very low (only 6 parents contacted the researcher). In addition, early participants informed the researcher that other parents were discouraged from participating due to the advertised 90-minute time commitment (to account for a meal, consent process, and focus group of 8-10 people). In community studies, researchers can enhance participant recruitment by being present in community settings and through informal conversations with prospective participants 
(Sixsmith, Boneham, \& Goldring, 2003). At the suggestion of Mr. Greenwell, the researcher attended and spoke with parents about the study at MAC activities, including youth basketball, gymnastics, cheerleading, and the REC League Afterschool Program, a MAC childcare program that includes structured physical activity and homework support, during the months of November 2014 - January 2015. At this time, the researcher clarified that the time commitment would likely be less than an hour, as the interviews would be in smaller groups or conducted individually.

The researcher also experienced difficulties recruiting males to participate in the study. Only three males signed up for the study via all recruitment efforts (one was ineligible and one later withdrew from the study). When speaking with fathers at MAC events about the study, the researcher was met with comments such as, "Give my wife a call, she'll be happy to talk to you..." and "You'll have to talk to my wife, she handles the kids' stuff." Butera (2006) describes the difficulties in recruiting men as participants in qualitative research interviews, particularly among couples who maintain traditional gender roles as they may view such a task as "household labor" (p. 1270). While most men did supply their wives' contact information, they were unwilling to be interviewed themselves.

As a result of multiple recruitment efforts, a total of 28 individuals signed up for the study over a three-month recruitment period. Two were ineligible (one did not have a child who had participated in a MAC program, one was a member of MAC staff). An additional 5 later declined to participate ( 2 actively withdrew, 3 failed to show up for their scheduled focus group and did not respond to follow up calls or emails). Ritchie, Lewis, Elam, Tennant, and Rahim (2014) point out that project budget and available 
resources may affect recruitment and sample size. Although there was a small budget of $\$ 1,000$, the project budget was quickly exhausted and exceeded through mileage costs (Meade County is approximately a 1-hour drive each way from Louisville), food costs for incentives, and transcription services.

In addition to recruitment challenges, focus groups proved logistically difficult to schedule around the busy lifestyles of parents. Even though reminder calls were placed two days prior to the focus group date, during the first two scheduled focus groups in November, all but one participant canceled at the last minute or failed to attend without notice. This resulted in conducting individual interviews with these first two participants. In addition to low recruitment numbers, participant schedules posed a further challenge to scheduling focus groups. Additional individual interviews were scheduled to accommodate participants who were unable to meet at times other participants were available for focus groups.

\section{Data Collection}

Study data were collected through semi-structured individual interviews $(\mathrm{n}=8)$ and 4 focus groups $(\mathrm{n}=13)$ during the months of November 2014 - January 2015. Participants completed a demographic questionnaire immediately following the interviews.

\section{Development of Semi-Structured Guide}

This study employed a semi-structured interview guide as the primary data collection method. Within the continuum of verbal data collection, semi-structured interviews follow a degree of predetermination with a list of questions or topics to be covered, but are generally comprised of open-ended questions with built in flexibility for 
the moderator (Gillham, 2000). The interview guide contains a list of these questions or topics for the moderator to cover. This ensures that there will be relative consistency across multiple focus groups and interviews and that the same questions will be asked in the same sequence (Morgan, 1997).

Gillham (2000) organizes the research interview into four phases: the introductory phase, the opening development of the interview, the central core of the interview, and bringing the interview to a close (both socially and in terms of content). Similarly, Charmaz (2006) proposes an interview structure consisting of initial open-ended questions, intermediate questions, and ending questions. Central core questions centered on parent and child physical activity health behaviors with rooting in theoretical constructs from the Social Ecological Model and Social Cognitive Theory (Bandura, 1989; McLeroy et al., 1988). Three questions were adapted from a qualitative study of parent influence on child physical activity that utilized tenets of Social Cognitive Theory (Wright, Wilson, Griffin, \& Evans, 2010). The structure and theoretical basis of questions are presented in Table 2.

Initial drafts of the interview guide were reviewed by a panel of experts to identify any questions that were dichotomous, leading, long, double-barreled, or contained jargon. Questions were also reviewed to assure that they elicited responses based on actual experiences, not opinions. The panel consisted of members of this project's dissertation committee who are methodological and content experts as well as members of the MAC board and staff who are standpoint experts. The guide was revised to assure that all questions were open-ended, neutral, clear, simply stated, and singular (Charmaz, 2006; Pavlish \& Pharris, 2012). The interview guide approved by the 
University of Louisville IRB and used during focus groups and individual interviews can be found in Appendix C. 
Table 2. Focus group questions.

\begin{tabular}{lll}
\hline Focus group questions & Theory & Construct
\end{tabular}

Introductory questions

1. So that we can record your voice for the Icebreaker N/A tape, please go around the room, introduce yourself by nickname, and tell how long you've lived in Meade County.

2. Tell me about your community. How would you describe your community in terms of physical activity in children and adults?

\section{Child PA behaviors}

1. What types of physical activities do your children do?*

2. I'd like you to discuss if the MAC project has influenced your children's physical activity.

\section{Parent PA behaviors}

1. What types of physical activities do you do?

2. Tell me about how you and your children are physically active together*

How have your children reacted when you've asked them to do some kind of physical activity with you?

How have you reacted when your children have asked you to do some kind of physical activity with them?

3. Describe the availability and accessibility of physical activity opportunities for adults here in Meade County.

4. How has your children's involvement in MAC activities affected you? Can you give me some examples?

Social Cognitive Role modeling Theory

Social Ecological Interpersonal level Model

Social Cognitive Theory

Social Cognitive Theory

Social Ecological

Community level (Social norms)
Role modeling

Reciprocity

\section{Final questions}

1. What didn't I ask you today that you expected me to ask?

Social Ecological Model Social Ecological Model

\footnotetext{
*adapted from (Wright et al., 2010)
} 


\section{Development of Demographic Questionnaire}

A short questionnaire was employed to record descriptive information about participants. The participant questionnaire collected data on demographic information, individual physical activity and MAC program participation, and child physical activity and MAC program participation. This information was used to develop a demographic profile of participants and to allow for deeper data analysis and comparisons across groups. The questionnaire was administered following the conclusion of the focus groups and interviews, so not to lead the participants in their responses. The demographic questionnaire approved by the University of Louisville IRB and used during focus groups and interviews can be found in Appendix D.

\section{Protection of Human Subjects and Ethical Considerations}

Risks to participants were mitigated through compliance with the university's IRB. During focus groups and interviews, subjects used pseudonyms to assure confidentiality. Neither the tapes nor the transcripts contained identifying information. Pseudonyms were also employed for the demographic survey. Collected data were continuously stored in either a locked filing cabinet or on a password-protected computer. Only the research team had access to the materials. All data were kept confidential to the extent permitted by law. Should the data from this study be published, all identifiers will continue to be protected. All study personnel who consented subjects, collected data, or assisted in analyzing data were certified through the Collaborative Institutional Training Initiative (CITI) and approved through the IRB.

The ethical principal of beneficence was accounted for as the potential benefits of participating in the study were equal to or outweighed the potential harms (U.S. 
Department of Health Education \& Welfare, 1979). There were no known risks to human subjects, except possible fatigue, boredom, embarrassment, stress, or frustration. To alleviate this risk, participation in the focus group interviews was voluntary. Subjects were free to not participate in the study or decline to answer any question or questions that made them uncomfortable. There were no known benefits to human subjects with the exception of possible improvements to MAC activities and services as a result of the study findings. Participants were not paid for their participation, though a meal was provided. The possible benefits to the field of health promotion may include increased knowledge of child influence on parent physical activity behaviors and informing other community-based physical activity interventions in rural, low socioeconomic populations.

Respect for persons throughout the study was accounted for through the informed consent process (U.S. Department of Health Education \& Welfare, 1979). Prior to the start of the focus group interviews, the researchers carefully explained the purpose of the study and outlined rules and guidelines for all participants. The researchers distributed copies of and explained the consent form and read key parts of the form. Subjects then had 10 minutes to review the consent. The subjects were allowed to ask questions, and were informed that taking part in this study was voluntary. Once all questions were answered, subjects signed two copies of the consent form and returned them to the researcher. The researcher signed both copies and returned one to the subject to keep for his or her records if they had follow up questions or concerns. Subjects did not have to answer any questions that made them uncomfortable. Subjects could choose not to participate at any time. The research team closely oversaw data collection and assured 
confidentiality at every point during this study. The IRB informed consent document can be found in Appendix E.

\section{Procedures}

With the exception of one individual interview, all focus groups and individual interviews were held in a private room at the Meade County Public Library, as this was deemed to be a familiar, accessible, safe, quiet and comfortable setting for participants (Krueger \& Casey, 2009; Morgan, 1997). One individual interview was conducted in a private room at James R. Allen Freshman Academy following a MAC basketball game. Chairs and tables were arranged in a circle that included all participants and researchers. Name tents were provided for each participant to fill out with pseudonyms. Focus group discussions and interviews were captured through two digital audio recording devices, following the consent process. A meal was provided before each focus group to promote conversation and communication within the group. Food was also provided as an incentive for those participating in individual interviews.

The researcher moderated and facilitated all focus groups and interviews, with the exception of two interviews, with which a co-moderator served as note-taker. A prepared and skilled moderator is critical to the success of focus group interviews. Moderators should be confident, organized (but willing to adapt), professional (but approachable), and informed on the issue (while recognizing that the participants are the true experts on their own experiences) (Krueger \& Casey, 2009). Throughout the focus groups and individual interviews, the moderator guided the discussions utilizing appropriate probes and pauses, and adjusting the semi-structured guide and questions accordingly (Gillham, 2000; Krueger \& Casey, 2009). The moderator also managed the time, made sure that 
participants focused on experiences and not opinions, and assured that all participants had a chance to share. Reflective listening was employed to summarize and confirm participants' statements (Gillham, 2000). Similarly, at the end of each focus group or interview, the moderator provided a brief summary of responses to important questions, which allowed participants to offer additions or corrections to the summary (Gillham, 2000). The researcher and co-moderator, when present, recorded general notes on the discussions, with emphasis on important quotes and behavioral observations (nonverbal and body language) that add to the meaning of participant words and phrases (Krueger \& Casey, 2009).

\section{Data Analysis}

Doctoral students and beginning researchers are encouraged to manually analyze qualitative data and cautioned in using computer assisted qualitative data analysis software (CAQDAS) (Krueger \& Casey, 2009; Patton, 2002). The researcher had previous experience in manual coding from two prior qualitative studies, and had funding to purchase CAQDAS. Qualitative studies generate a considerable amount of data, and it is important that these data be analyzed in a way that is thorough and transparent. Hand coding is time consuming and labor intensive, even when working with a small number of interviews (Creswell, 2014). For projects requiring more than 25 hours of coding, Auld et al. (2007) suggest researchers consider using CAQDAS as a data analysis tool. It was determined that QSR NVivo 10, a CAQDAS software package, would aid greatly in comparing concepts and codes across properties and dimensions when analyzing according to grounded theory. Thus, NVivo was employed as a data analysis tool. 
The recorded focus group sessions and individual interviews were transcribed verbatim by an outside agency. Upon completion, the transcripts were checked for accuracy by the researcher against the original audio recordings. Transcripts were uploaded into NVivo. Data obtained through the demographic questionnaire were entered into an excel spreadsheet and uploaded to NVivo. A case node was created for each focus group participant connecting them to these data, and their comments were auto coded to this node throughout the transcript. Notes, behavioral observations, and memos recorded by the moderator and co-moderator were also uploaded and added as nodes to the respective focus groups.

All transcripts were initially read in their entirety prior to beginning the coding process in order to enhance familiarity with the data. Coding refers to "categorizing segments of data with a short name that simultaneously summarizes and accounts for each piece of data" (Charmaz, 2006, p. 43). Grounded theory utilizes three phases of coding: open (generating categories), axial (systematically developing and linking categories), and selective/theoretical (integrating and refining categories) coding (Charmaz, 2006).

\section{Coding}

Open coding was employed as data were collected and transcripts were completed. Initially, transcripts were analyzed line-by-line using open coding in NVivo. Codes were generated by creating labels for preliminary concepts as well as "in vivo" codes (respondents' exact words). A case node was created for each respondent, which contained all of his or her responses. 
Case nodes were also created for the 8 main questions (excluding the final question) in the interview guide. The responses to each of these questions were coded to the respective node to allow comparison of responses across interviews. Each time a new transcript was completed, it was uploaded to NVivo, coded line-by-line, and responses were coded into the appropriate question case node. This allowed for constant comparison across interviews and a back-and-forth interplay with the data. Hunches, ideas, and questions about relationships and possible theories were recorded in memos. After all transcripts were uploaded to NVivo, Word Frequency and Text Search queries were conducted to assist with coding and comparison across transcripts. Duplicate codes were merged and code names were refined.

The process of open coding generated 45 codes. There were 12 sources of data collection, 8 individual interviews and 4 focus groups. Table 3 presents the results of open coding, including the number of data sources where these themes were found and the total number of times each theme was coded (references). 
Table 3. Open codes (total sources $=12$ ).

\begin{tabular}{|c|c|c|}
\hline Code & Sources & References \\
\hline Adult PA at Home & 6 & 8 \\
\hline Adult PA through Faith Community & 3 & 5 \\
\hline Adult Physical Activities & 5 & 5 \\
\hline Barriers to Parent PA & 4 & 13 \\
\hline Child MAC Participation Adds Stress on Parent & 4 & 4 \\
\hline Child Screen Time & 7 & 14 \\
\hline Children as Motivation for PA & 4 & 5 \\
\hline Children Initiate Parent PA & 11 & 19 \\
\hline Children Used as Communication Channel & 3 & 7 \\
\hline Community & 9 & 14 \\
\hline Community Adults are Inactive & 4 & 10 \\
\hline Community PA Opportunities and Resources & 4 & 21 \\
\hline Commuting & 6 & 9 \\
\hline Division of Meade County & 3 & 6 \\
\hline Family Oriented Community & 4 & 6 \\
\hline Family PA & 12 & 38 \\
\hline Farming & 4 & 10 \\
\hline Financial Barriers & 6 & 21 \\
\hline Improved Academic Performance & 5 & 9 \\
\hline Increased Community Awareness of PA & 8 & 17 \\
\hline Kids Enjoy MAC Programs & 5 & 9 \\
\hline Lack of Indoor Spaces & 7 & 23 \\
\hline Lack of PA Options for Adults & 8 & 26 \\
\hline MAC Allows Children to Explore Different Sports & 7 & 8 \\
\hline MAC as Childcare & 7 & 16 \\
\hline MAC Exposes Children to Role Models & 4 & 5 \\
\hline MAC Helps in Promoting Healthy Behaviors to Children & 3 & 6 \\
\hline MAC Not Serving All Meade Children & 3 & 6 \\
\hline Military Community & 7 & 13 \\
\hline Need for Adult Programming at All Skill Levels & 3 & 5 \\
\hline Need for Community Facility for Adults and Children & 7 & 16 \\
\hline Older Kids Not Interested in Joint PA & 4 & 6 \\
\hline Organization of MAC Programming & 5 & 9 \\
\hline Outdoor and Seasonal PA Opportunities & 11 & 61 \\
\hline Outsiders & 4 & 6 \\
\hline PA in Borrowed Spaces & 8 & 17 \\
\hline PA Outside of Meade County & 10 & 18 \\
\hline Parents Upset by Fitnessgram & 2 & 4 \\
\hline Safety Concerns at Available PA Spaces & 5 & 7 \\
\hline Scheduling Demands of Parents & 6 & 10 \\
\hline Schools as Source of Change & 6 & 13 \\
\hline Sense of Community Belonging & 6 & 13 \\
\hline Social Growth in Children & 8 & 19 \\
\hline Suggestions for Adolescent Programming & 1 & 5 \\
\hline Video Games as Physical Activity & 5 & 11 \\
\hline
\end{tabular}


Axial coding was employed to explore the relationships and connections between initial codes. Conceptual categories were created and grouped into main and subcategories. Categories and subcategories were further examined across contextual, demographic, and experiential properties to link these relationships. Referral to field notes and earlier memos guided this process.

Selective codes were created by connecting and consolidating axial codes, which identified core themes (constructs). Transcripts were again reviewed to code any relevant data that were previously overlooked. For studies utilizing a grounded theory design, Charmaz (2006) prescribes for researchers to collect data to the point of theoretical saturation, that is, when no new properties or insights emerge from subsequent sampling and data collection. Theoretical saturation was reached after interviewing 21 participants, as no new information was attained from the final two focus groups conducted. Although this sample size was arguably small, it was appropriate given the study design and population parameters. Creswell (2014) advises that 20-30 individuals are typically needed to reach saturation for grounded theory studies. Green and Thorogood (2009) add that "the experience of most qualitative researchers (emphasis added) is that in interview studies, little that is 'new' comes out after you have interviewed 20 or so people” (p. 120). In addition, (Charmaz, 2006) suggests that the aims of the study, such as those describing the experience of a specific group or population, may lead to earlier saturation than those in which the aims are to describe "human nature or contradict established research" (p. 114). Given that this study investigated the experiences of parents of child participants in a specific community program, it is logical that saturation was achieved 
early on. Results from all levels of coding as well as the theoretical model representing the influence of the MAC on parent physical activity are shared in the next chapter of this text.

\section{Ensuring Quality and Rigor}

Methods to assure qualitative rigor were employed throughout data collection and analysis. Lincoln and Guba (1985) suggest trustworthiness of a qualitative research study as essential to evaluating rigor and worth. They propose the concepts of credibility, transferability, dependability, and confirmability as strategies to establish trustworthiness and increase the quality of qualitative research (Lincoln \& Guba, 1985).

Credibility, or confidence in the "truth" of the findings, is "considered qualitative research's analog to quantitative research's concept of internal validity" (Cottrell et al., 2010, p. 241). All members of this dissertation committee served as peer debriefers, reviewing the codes and categories assigned during the data analysis process to enhance credibility and ensure validity. Triangulation, using multiple data sources to build coherent themes, is one strategy used to establish study credibility. Triangulation of sources was measured in this study by running matrix coding queries in NVivo to quantify the number of different participants who talked about various concepts and codes, systematically examining similarities and differences in responses across attributes.

Dependability, demonstrating that findings are consistent and could be repeated, is similar to reliability in quantitative research (Cottrell et al., 2010; Lincoln \& Guba, 1985). Confirmability in qualitative research refers to the extent to which the findings are shaped by the respondents, not the researcher, ensuring the findings are free of bias (Lincoln \& Guba, 1985). Data analysis in NVivo assured dependability and confirmabilty 
for this study by providing a detailed audit trail carefully documenting all research, and allowing for researchers to review their trail of decisions and confirm that conclusions are grounded in research data.

Transferability in qualitative research is related to external validity or generalizability (Cottrell et al., 2010; Lincoln \& Guba, 1985). While generalizability is not the goal of qualitative studies, findings may be applicable in other populations and contexts. Detailed, thick, rich descriptions of the data analysis process and study findings are provided in chapters $4-5$ in order to aid in the evaluation of transferability of these findings to other settings.

\section{Summary}

This chapter presents the research design, participant recruitment procedures, data collection methods, and data analysis methods used in this study. Challenges in the recruitment and data collection processes were documented and discussed along with strategies employed to address these issues. Results of the data analysis are presented in Chapter 4. 


\section{CHAPTER IV}

\section{RESULTS}

\section{Introduction}

This chapter shares the findings of the project. The purpose of this study was to assess the influence of child participation in physical activity programs on adult physical activity in a rural community. As described in chapter 3, a grounded theoretical approach was used to analyze data from focus groups and individual interviews conducted with 21 parents of Meade Activity Center (MAC) participants. Data from interview and focus group transcripts were coded following open, axial, and selective coding processes. Selective coding resulted in the formation of four main conceptual findings.

This chapter includes 5 main sections. Demographic characteristics of the study participants are provided. The constructs that resulted from selective coding of data are labeled "Family is Central to Community Identity," "Increased Community Priority in Physical Activity," "Children Influence Parent Physical Activity," and "Barriers to Parent Physical Activity." Each construct is discussed in detail with more specific subcategories considered under these main themes. Direct quotations are provided to assist in illustrating each concept and subcategory, and to aid in the understanding of the interrelationships between categories. Findings propose that increasing access to community spaces where families can be physically active together will optimize the 
bidirectional influence of parent-child physical activity, thus increasing adult physical activity in Meade County.

\section{Participants}

Over a three-month period of data collection, an opportunity sample of 21 parents participated in the study through individual interviews $(\mathrm{n}=8)$ and 4 focus groups $(\mathrm{n}=$ 13). Table 4 provides the demographic characteristics of the parent participants reported as frequencies and percentages. Parents ranged in age from 27-50 years old, with a mean age of 39.2 years. Participants were mostly female (95\%). Some of the parents had lived in the community all of their lives, while some were newcomers. The average length of time in Meade County was 19.3 years, though this ranged from 7 months to 48 years. Sixty-two percent had a college degree and the majority (76\%) were employed full-time. All participants were married. Based on self-reported physical activity, only 6 of the participants met the minimum recommendation of 150 minutes per week of moderateintensity physical activity (U. S. Department of Health and Human Services, 2008). In addition, only 6 of the parents indicated that they had participated in any of the MAC adult programs (4 participated in a 5k, 1 swimming, and 1 zumba).

Parents also provided age and gender data on their children, and reported on their involvement with the MAC and physical activity levels. Table 5 presents this information on the participants' 40 children. Children ranged in age from 1-22 years. Parents classified 58\% of their children as "Frequent MAC Participants". Thirty-five percent of the children had participated in MAC programs for 3 or more years. Results from the focus groups and individual interviews with participants are detailed in the following sections and presented as four main constructs and subcategories. 
Table 4. Demographic characteristics of sample $(n=21)$

\begin{tabular}{lrl}
\hline Characteristics & Freq & $(\%)$ \\
\hline Gender & & \\
Male & 1 & $(5)$ \\
Female & 20 & $(95)$ \\
Race/Ethnicity & & \\
Non-Hispanic White & 20 & $(95)$ \\
Native American & 1 & $(5)$ \\
Time in Meade County, years & & \\
Mean (Range) & 19.3 & $(7 \mathrm{mo.}-48 \mathrm{yrs})$. \\
$0-4$ & 4 & $(19)$ \\
$5-9$ & 3 & $(14)$ \\
$10-19$ & 5 & $(24)$ \\
$20-29$ & 2 & $(10)$ \\
$30-39$ & 4 & $(19)$ \\
$40+$ & 3 & $(14)$ \\
Education & & \\
Some college/technical training & 2 & $(10)$ \\
Technical/Associates Degree & 6 & $(28)$ \\
College Degree & 13 & $(62)$ \\
Work Status & & \\
Full-time & 16 & $(76)$ \\
Part-time/Seasonal & 3 & $(14)$ \\
Homemaker & 2 & $(10)$ \\
Marital Status & & \\
Married & 21 & $(100)$ \\
Level of Physical Activity, times/week $\geq 30$ min moderate PA)* & & \\
$<1$ & 5 & $(24)$ \\
$1-2$ & 2 & $(10)$ \\
$3-4$ & 8 & $(38)$ \\
$5-6$ & 5 & $(24)$ \\
$7+$ & 1 & $(5)$ \\
Number of Children & & \\
1 child & 10 & $(47)$ \\
2 children & 4 & $(19)$ \\
3 children & 6 & $(29)$ \\
4 children & 1 & $(5)$ \\
& & \\
& & \\
& &
\end{tabular}

*Percentages do not add to 100 due to rounding 
Table 5. Child characteristics and MAC involvement

\begin{tabular}{lrl}
\hline Children of Participants & Freq & $(\%)$ \\
\hline & & \\
Age, years & 4 & $(10)$ \\
$0-4$ & 24 & $(60)$ \\
$5-9$ & 8 & $(20)$ \\
$10-14$ & 1 & $(3)$ \\
$15-18$ & 3 & $(7)$ \\
$>18$ & & \\
Gender & 18 & $(45)$ \\
Male & 22 & $(55)$ \\
Female & & \\
Years in MAC & 2 & $(5)$ \\
0 & 16 & $(40)$ \\
1 & 8 & $(20)$ \\
2 & 14 & $(35)$ \\
$3+$ & & \\
Number of MAC Activities per Year & 2 & $(5)$ \\
0 & 19 & $(47)$ \\
1 & 6 & $(15)$ \\
2 & 8 & $(20)$ \\
3 & 5 & $(13)$ \\
$4+$ & 3 & $(7)$ \\
Level of Physical Activity (days/week 60 min of moderate-to-vigorous & PA) \\
0 & 3 & $(10)$ \\
1 & 6 & $(15)$ \\
2 & 6 & $(15)$ \\
3 & 5 & $(13)$ \\
4 & 10 & $(25)$ \\
5 & 0 & $(0)$ \\
6 & 6 & $(15)$ \\
7 & & \\
& & \\
& &
\end{tabular}




\section{Family is Central to Community Identity}

When describing the Meade County community, all participants spoke of the importance of family. Participants discussed characteristics of what differentiates their "tight," "supportive," and "close-knit," and "family-centered" community from others. Although not directly related to physical activity, this concept is very important as it has key implications for the other three conceptual findings. As family and children are central to adults in this community, interventions that target children may have implications on other family members. Responses provide insight into the context and meaning of these unique community characteristics.

\section{Community Support and Shared Parenting}

Parents expressed a sense of security and support in raising children, and viewed the community as an extension of their own family. As a newcomer who had lived in the community for only one year described, 'I've noticed just since I've been here, how friendly and helpful everyone is, no matter where you go in the store or whatever, people treat you as if they've known you for your whole life." During one focus group, mothers were brought to tears when discussing the recent death of a Meade County child, "It is a very supportive community... [a] recent young person's death in the county, I think the entire county's pretty emotional from that and very supportive of this family."

Parents discussed the comfort in knowing that they can rely on other parents and community members to look out for the best interest of all community children. As a 45year-old Native American mother of a 12-year-old daughter explained:

We feel like if our child is at the movies and we allow her to go with somebody else, if the parent is with her, whether it's a military family or somebody, 
somebody in that movie theater is going to know us and they are going to walk down there and do something. So, it's a very tight-knit community. And it's not just worries for our own kid; we're invested in the whole community, everybody else's kid. It's a lot of volunteering, a lot of taking care of other kids. If this person doesn't have something, we make sure we get it for them. If your child

[needs] something, it's definitely pushed to another family, sharing stuff.

Part of this is a result of social connections and knowing so many members of this small community. One mother summed it up saying, "I know my neighbors. I know my neighbor's kids. I know my neighbors' cousins." Residents view the community as an extension of their own families and take on the responsibility to help and care for each other.

\section{Children Vital to Parent Social Connections}

Children were described as central to parents' identities and social circles. Social networks are formed with parents of other children. When discussing her social circle, a 33-year-old mother of two explained, "[We] all have kids... that's pretty much [what] brought us together. My world revolves around my children."

For community newcomers, child participation in the MAC programs has been key to friendships and community connections for both children and adults. A 50-yearold female described how the MAC helped her son make friends since they recently relocated to Meade County from Louisville:

I think that when you, like in Louisville, you know your houses are so close together, if you see people all the time, the kids have other friends that are close. When you move out in a rural area you can't just walk to your friend's house, so 
with having programs at the MAC, especially the after school program for me has been a huge plus, because my son didn't know anyone down here as far as his age or going to school. The afterschool program, he's met a few children there, honestly I don't know what I'd do without the afterschool program.

The connections that the children have made through the MAC also helped adults make friendships and connections in the community. A father of three explained, "When you go in [to MAC programs] to get your kids, you know so many people and your kids know so many people. It just increases the community base when you know everyone." A 41-year-old mother who had lived in Meade County for two years shared her experience:

When I moved here I didn't know anybody, my husband was still in Virginia for a year. [My daughter] started the MAC camps and somehow school was starting, and I didn't know what I was going to do for after school care. Then we met his daughter [referring to another participant], being a counselor with the summer camps, and she became my daughter's after school babysitter. So she had to be all involved with their family, best friends with her kid, get to know all of his other kids.

\section{Selecting and Sacrificing to Live Here}

Many Meade County residents have strong roots and family history in the community. However, unlike many rural communities that are comprised of multigenerational and non-transient residents, Meade County also attracts many newcomers. New residents choose to settle in Meade County over other areas specifically for the small town family feel and sense of community belonging. 
Many working adults commute to jobs at the military base at nearby Fort Knox, to employers in Louisville, or drive even farther in order to raise their family in this environment. One mother described her family's decision to relocate to Meade County when her daughter was an infant and the effect on her husband's daily commute:

My husband drives an hour and 20 minutes to work, and an hour and 20 minutes back from work just to have my daughter in this environment where she goes to school. We feel comfortable that if she acts up, the schoolteachers and the family will take care of it just like we would.

A 34-year-old military wife and civilian employee at Fort Knox said, "We picked Meade County specifically, [over Hardin County] because we like the smaller towns." Twelve of the participants expressed that at least one of the adults in their household commuted to work outside of Meade County each day. Adults in the community choose to endure what are often long commutes, and view that the net benefit of raising their children in this community outweighs the related time and travel expenses.

\section{Increased Community Priority in Physical Activity}

Throughout the focus groups and individual interviews, participants identified an increased community awareness surrounding physical activity following the inception of the MAC. While MAC programs sparked change in the community, other organizations and agencies in the community have assisted in promoting physical activity to residents of Meade County. A 34-year-old mother of one described the changes she's seen as, "The community as a whole is trying to drive kids [to be more physically active]. In doing so, it impacts a family as a whole... It definitely starts with the family." New initiatives targeting children, adults, or entire families are present in the community. 


\section{MAC Contributions}

Parents identified the MAC as the catalyst for changes in community physical activity. A lifelong resident of Meade County described the recent changes within the community:

I think probably over the past few years the county has become more involved by having $5 \mathrm{~K}$ 's, different things like that, putting more funds into parks and recreational areas down by the boat docks, keeping up and maintaining the Buttermilk Falls area, which is a great area for families to go and enjoy physical activity, run, bike, etc. With the inception of the MAC center, I think it's definitely brought some awareness to the community regarding physical health and the importance of it.

The MAC has had both a direct and indirect influence in increasing physical activity within the community. The community is demonstrating a commitment to physical activity by investing resources in public spaces.

Community children are exposed to a variety of sports and physical activity opportunities through MAC programming. Parents view MAC programs as a tool to help in promoting healthy behaviors in their children. A 44-year-old mother of three described the influence of the MAC programs:

I think it [the MAC] made them excited. I think it's given them something to be excited about. My generation, exercise is not necessarily exciting or not everyone looks forward to exercising, but I think what I'm trying to teach and I think the MAC promotes it, is to instill in a young age that it's just your lifestyle. It's not a chore. It's not something that you have to dread doing. It's just part of your 
everyday routine, and you don't know any different. That's the way I look at it with my girls. If they start now, it's not going to be a chore for them. It's going to be routine... My parents did not exercise... I don't think it was ever enforced or a priority. It wasn’t encouraged.

MAC programs normalize physical activity for the children of Meade County. Parents are hopeful that this will lead to lifelong healthy behaviors.

The MAC has also hosted or partnered on several community races, such as run/walks and cycling events. Participants identified the MAC Holiday Fitness Series consisting of three races as a new community effort. In addition to promoting physical activity to Meade County residents, these are events that families can participate in together.

\section{Schools Facilitate Change}

As an organization, the Meade County Schools system has been instrumental in leading the changes in the community. County schools have served as essential partners to the MAC initiative, with elementary schools implementing bi-annual fitness and health testing within the physical education curriculum. In addition to physically housing many of the MAC programs for children in school gymnasiums and facilities, community children engage in school sports. While parents negatively commented on less time in the actual school day dedicated to physical activity due to curriculum restrictions, there are many after hours physical activity programs and initiatives provided by the schools.

Independent of MAC programming, school sports were identified as highly important within the community, with schools offering many new sports programs. Seven of the participants spoke about their children participating in the school cross country 
program coordinated through Meade County elementary schools. A mother of three who had been a resident of Meade County since early childhood recounted:

I remember when I was in high school I didn't really participate in sports, but like she said, sports are huge. They do have a lot of programs, my kids' school a few months ago, did a $5 \mathrm{k}$ at the school... she's [only] in fourth grade!

A 48-year-old mother of four explained the structure of the program:

We also have cross country and all of the schools have a cross country team now and all the kids third grade and up are encouraged to participate with that. They have a practice once a week for about an hour and then they have meets and we switch schools and they run a mile.

Another participant described her reactions to the first cross country meet she attended while watching her 8-year-old daughter compete:

It's huge! The first meet, I had no idea that there were over 300 kids there across the community, across the county, just running for the sheer pleasure of running and competing. They do a great job. That's a great opportunity for kids to get excited about exercising... I was astounded at the representation from each of the schools and the number of kids that were there, like I said, just running for sheer joy of running, and the parents that were there supporting them.

Meade County Schools do more than just provide sports programs for enrolled children; they promote physical activity for entire families. Six of the participants described their experiences participating in family fitness nights at Brandenburg Primary School that started during the 2013-2014 academic year. A mother detailed the structure and establishment of the program: 
I know at Brandenburg primary school they have family fitness night. And once a month, it's usually on a Monday, families are encouraged to come and they have a walking station and then some other kind of activity. We've done zumba, yoga, I can't remember all of them. But the families come on and participate for an hour or so and they $\log$ in their time and they keep track of that. The children get little tokens for their shoes to show that they participated and are logging activity hours... Mr. Pollock at the school [started it]. He's the physical education teacher at Brandenburg Primary. Matt Pollock is somehow affiliated with the MAC, but I think he started this on his own about a year ago. About 40 families participate. Other primary schools have talked about starting something similar.

In regards to family fitness night and the role of schools in implementing new programming, a 41-year-old mother of one simply stated, “They're always coming up with something. At the school now they have the family fitness night, we did that. My schools never did anything like that, so I think it's really becoming a focus."

\section{Other Community Events and Programs}

Outside of the MAC and Meade County Schools, parents identified other new opportunities for physical activity within the community. Participants indicated that investments have been made to upkeep and enhance community parks, walking trails, and other public spaces to enhance opportunities for Meade County residents to live active lives. Recently implemented zumba, yoga, and pilates classes are offered for adults free of charge in community meeting rooms at the Meade County Public Library. Participants highlighted a new CrossFit facility that opened for adults in January 2015. In addition to 
MAC affiliated events, parents identified other new community running and walking races.

\section{Children Influence Parent Physical Activity}

The participants were asked about the types of physical activity that they engage in. When reporting physical activity that they completed on their own or with other adults, responses were quite limited with most participants only naming one activity or no activity at all. This corresponds to the low self-reported physical activity levels on the demographic questionnaire. However, when they described physical activities that they engaged in with their children, responses were much more diverse. Parent physical activity in Meade County relies heavily on joint activities that families participate in together.

\section{Parent Physical Activity}

Four participants indicated that they walk outside in their neighborhood or at a local park or trail. Four other parents reported running as their primary form of physical activity, three of which had access to a treadmill in their home. Only three of the participants belonged to a gym, with two holding memberships to facilities outside of Meade County. Two participants reported working out at home by themselves, one with an elliptical trainer and the other through setting up weights and circuit training. Only one participant mentioned working out with other adults, setting up group training several days per week on a rotating schedule in the homes of church group members.

Other participants seemed to draw a blank when thinking about physical activity that they engage in. A 43-year-old mother of three responded, "Aside from if you count housework, I'm not getting any physical activity." Two parents reported housework as 
the only form of physical activity that they are engaged in, three parents mentioned light farming, and two parents indicated they were not currently involved in any form of physical activity.

\section{Family Physical Activity}

Responses starkly differed when parents were asked about physical activity that they engage in along with their children or as a family unit. All participants reported being physically active with their kids. Parents talked about a wide range of activities including family bike rides, walks, playing catch, and water sports, which they practiced with regularity during summer months. Parents also spoke of participating in community races and fitness events with their children, though these activities were more infrequent. Table 6 provides an outline of the types of physical activities participants engage in with their children, with indication of how many reported each.

Table 6. Family physical activity

\begin{tabular}{lc}
\hline Physical Activity & Number of Participants \\
\hline Walking & 16 \\
Swimming & 10 \\
Practicing Child Sports & 8 \\
Community Races & 3 \\
House Play & 5 \\
Biking & 8 \\
Video Games/Exercise DVDs & 7 \\
\hline
\end{tabular}

Parents talked about the value of spending time together as a family while taking part in these activities. A community newcomer talked about her family's use of Buttermilk Falls:

I can't tell you how much that trail has helped our family just in general as far as being able to be active and feel safe, have a place to go where we can bike ride or 
walk or push the buggy. That helps us a lot. It's a relaxing place so you don't hate to go. When you are dealing with traffic or whatever in other places you just dread it a little bit. I don't dread it here because there is a safe place to go.

Participants also spoke of being more active as a family during the summer months when the weather was nice to accommodate walking trails, bike riding, and water sports. Participants recounted going on family walks each night during summertime. A mother who described herself as "inactive" explained, "It's just easier to do things together outside in the summertime. The main things we do together are swimming, walking, and hiking... the weather doesn't allow that in the wintertime."

Families also engage in physical activity inside of their own homes. Several of the parents referenced video game consoles such as Nintendo Wii Fit and Kinect for Xbox 360. Participants spoke of frequently playing these fitness, dancing, and sports games as a family. A 46-year-old father of three, who had reported that he did not engage in any physical activity on his own, described his family's use of the Kinect program:

That's the big thing in the house now... I thought I was going to have a stroke one day when I was playing. My wife, and my kids they're very competitive in it to see who can do the best because they can do it together. I have tried it, and yes,

I'm a little fat. But I would advise getting it. It will definitely give you a workout. Others shared similar experiences using exercise video games or playing fitness DVDs along with their children.

\section{Bidirectional Influence}

When discussing parent-child joint physical activity, parents were asked to provide examples of times when each party had asked the other to be physically active 
with them. Participants revealed that parents and children encourage and motivate each other to be physically active. Younger children initiated joint physical activity more often than adolescents, as adolescents were less likely to engage in any activity with their parents.

Most parents categorized initiation of parent-child joint physical activity as a "50/50" relationship. One mother described how she and her 7-year-old son motivate each other to be active; "I think that we do a little bit of both. My son maybe more probably than we do, but we may suggest something, but a lot of times he'll say, 'Can we go to...' So it's probably a little bit of both."

Differences in child age and initiation were distinct. A mother described how her 6-year-old daughter initiates physical activity in her household:

She's very active. She would go swimming every day in the summer, if I'd take her. She doesn't sit still a whole lot, either. She's always putting in the Wii and the Just Dance, and she can't do it alone, so I have to get up and do a dance, but that's okay...If it wasn't for her, she's much more active than I am. She's actually a good example for me, and she's the one who kind of motivates me when it should be the other way around. ... If it wasn't for her, I'm a little more of a couch potato, so, thank goodness. Then I'll try to tell myself I'm the one who's always complaining I want to do something. I just need to listen to her. Then I'll get up and do it and I'll be glad I did.

Another mother to a seven-year-old daughter shared similar experiences; "She probably encourages me as much or more so than I encourage her. She's like 'let's go walking, I want to ride my bike.' That's really good." 
In general, parents reported less joint physical activity with adolescent and teenaged children compared to younger children. In referring to joint physical activity, a mother of three reported, "The two little ones will come downstairs and try to do some [exercise] videos or something with me, but my oldest, he's not interested." When asked about initiating physical activity, older children rarely initiated physical activity, and were "reluctant" to join when their parents encouraged them to be active with them. A mother of three explained why her oldest daughter doesn't join her, "If I'm going to get pushback on something, it's not necessarily because it's exercise. It's just whatever she's doing might conflict.”

\section{Influence of Child MAC Participation}

Broadly, the MAC programs have boosted community awareness in regards to the importance of physical activity. In this unique community, parents and children are active together as families. Increased physical activity in community children produced both a direct and indirect influence in parent physical activity levels.

Child participation in MAC programs directly influence parent physical activity as children often practice sports at home with parents and other family members. In reference to her daughter's participation in MAC programs, one mother simply stated, "It has made me more active by making her more active.” As children are introduced to new and different sports through MAC programs, they share these experiences and engage other family members in these activities. A homemaker and 44-year-old mother of three described the influence of her child's participation in MAC soccer on her own physical activity: 
I think it's been good for us as a family because it gives the kids an opportunity to try different things. I've never played soccer as a kid, so it gives us a chance, and so as they're learning something we go home and we kick the soccer ball around. Another parent shared a similar experience resulting from her daughters' recent participation in MAC programming; "They're in taekwondo right now. I've never done that. I don't know the moves. They're teaching me."

Indirectly, parents are supportive of the MAC's efforts and encourage their children to be physically active. As a lifelong Meade County resident and mother of four explained, "There's more emphasis in the schools and the children know that they need to be active. And parents are encouraging that and trying to stay active with the kids." While parents may perceive that they are only providing social support and motivation for their children to be physically active, they are physically active along with them.

\section{Barriers to Parent Physical Activity}

While children do influence their parents' physical activity behaviors, that effect is mitigated by the availability and accessibility of physical activity opportunities and programming for adults in the community. Participants indicated that there are limited opportunities for adult physical activity in Meade County. Participants described current programs as expensive, inconsistent, and/or inconvenient for parents' busy schedules.

\section{Accessibility to Physical Activity}

Although there is an increased priority in physical activity at the community level, participants spoke of frustration with the few opportunities for adults. There are only two indoor spaces in the community dedicated to adult physical activity, Snap Fitness and Meade CrossFit, which recently opened in January 2015. Both of these facilities have 
limited hours and serve adults only, without childcare. There are additional financial barriers to access these facilities, as a membership to Snap Fitness is $\$ 35$ per month and a membership to Meade CrossFit is $\$ 110$ per month.

Participants identified several outdoor spaces within the community where they can be physically active such as Meade Olin Park and Buttermilk Falls. Many adults also run, walk, or ride bikes along neighborhood and community streets. Often, they indicated engaging in these activities as families with their children. However, participants only utilize these spaces seasonally. As a mother who reported that she participates in little to no physical activity each week explained:

It's hard in the wintertime for me to get physical activity. I like to be outside, but it is definitely challenging in the wintertime when it's cold and nasty out. In the summertime, we swim a lot. We walk. We go down to the Buttermilk Falls and walk and bike rides there like that. We're definitely lacking in the wintertime though. I don't like to be cold.

Participants identified other indoor opportunities for adult physical activity in Meade County, but these were held in borrowed spaces and offered at inconsistent times. The Meade County Public Library offers free zumba, yoga, and pilates classes for adults. However, only one of the study participants had attended these offerings, and that was only once. Participants were unsure of the times these classes were offered, or how to register for the programs. In addition, one participant commented, "It's at the library, and in the room at the front. I don't want people watching me sweat as they go to checkout books." Others indicated that some community members walk inside church gyms and 
schools, but they were unsure of the limited hours that community members had permission to attend.

Parents described the MAC adult program offerings as "seasonal" and "sporadic." They also reported poor communication and little promotion of MAC adult physical activity programs. In regards to adult programming, the MAC website was described as "confusing," "unclear," and "outdated," and discussed difficulties in finding information on or a listing of adult program options. Parents were also unsure of the benefits afforded by MAC membership, particularly for adults who were included in family memberships. Participants spoke of a desire for a greater breadth of adult program offerings on a more regular basis, and consistent locations.

\section{Time Constraints}

The majority of participants were employed full-time. In addition to the time constraints surrounding their work schedules, parents experience additional scheduling challenges resulting from child participation in activities, specifically sports and MAC programs. One mother commented on the strain she observes in community parents:

Ten years ago you took a kid to one sport. Now some of these kids... I have one kid, and she has archery practice on Tuesdays and Thursdays. And we have meets every Saturday. And two hours on each of those days and all day Saturday. The entire day. She will shoot at 12 o'clock and we have to be there at that meet until 9 o'clock for awards. So during that meet I cannot do anything else. I have one kid. Some of these people have five kids and they are literally running to all these soccer and whatever. I don't know how these parents can do anything. 
Parents also discussed the challenges of having multiple children enrolled in MAC programming. Because all MAC programs are conducted in borrowed spaces, programming for different age groups is held during different time periods, at various locations, and at different times. A mother of 3 spoke of the difficulties that these scheduling differences impose, "When you have three of them, you're running a lot... They're all in basketball right now. Different places, different times, same times, different places." Parents talked about many hours spent sitting and watching their kids participate in sports and physical activities. This allows for little time for parent physical activity.

\section{Lack of Childcare}

While child activities and schedules limit time, when parents do have the availability in their schedules, a lack of childcare imposes an additional barrier to adult physical activity. As one mother explained, "the adults [in Meade County] are pretty sedentary. Part of that is there's not a good place to go workout, with childcare." Parents spoke of not wanting to leave their children at home or with a caregiver. They spoke of feeling guilty and selfish in asking friends, family members, or neighbors to watch their children while they did something for themselves, by themselves. Parents also indicated that they were unwilling to pay someone to watch their children for this purpose. Mothers often neglect their own physical activity and health in favor of that of their children.

Participants who were physically active also identified childcare as a barrier. A homemaker disclosed that she commutes to workout facilities with her three children several days per week: 
I am very frustrated sometimes that the only gym facility we have is Snap Fitness. You can't take your children there, there's no childcare, it's not a family environment at all. So to go to the gym I've got to go Corydon or I've got to go to Louisville, and that's a huge disadvantage because sometimes you just don't want to drive a half an hour to go work out for an hour and then the half an hour back home.

A full-time employee and mother revealed that she gets up at 4:00 am 5 days each week to workout in her basement, before her children wake up. She further explained that if she did any physical activity outside of her house:

I'd have to [pay] somebody to watch my kids if I had to get out for an adult activity, and it's a lot of money when you've got three kids doing stuff. I can't afford to pay for me to go do stuff too, because I've got to pay for them to do stuff.

Seven of the participants indicated that they had fitness equipment at home such as a treadmill or an elliptical trainer, but also recognized that is not something everyone in the community can afford.

Another mother who reported that she exercises 7 days per week described the difference in taking her 6-year-old son with her to fitness facilities in Meade County and those she has access to through her husband's employment at Fort Knox:

[At Snap Fitness] we'll workout on the stuff that obviously he's not allowed to be on and then once it gets to a part where I can kind of incorporate him [into the workout] a little bit, he has an iPad and he plays on it for the 30 minutes that I'm doing whatever in the gym. And then I'll do legs or something that he can [do 
with me]...They have a table that he can sit at and he's been with us so much that he walks in and he sits down at the table until it's his turn to get with us. It is a little frustrating, it would be nice if there was something bigger or if there was just something more that he could do. On base they have a daycare where you can drop your kid off and they can play in a playroom and they have people that are staffed there, but that's not convenient and takes up too much time to drive there. While these mothers do manage to be physically active, the described circumstances identify the frustrations they endure. Many adults may not be willing to make those same sacrifices.

\section{Need for Family Space}

To address these barriers, nearly all participants expressed the desire for a community space where parents and children can be physically active together. One mother described her vision as:

[A place] where you can actually take your kids with you. They can do their exercise programs or whatever they have going on while the adults are doing their own. That way the whole family is getting their exercise in. They might not be in the same room, but they're there together.

While a physical building is a long-term goal of the MAC, these recommendations can further guide the development of a physical center and program offerings as the MAC moves forward with program planning for community adults and children.

\section{Summary}

The purpose of this study was to assess the influence of child participation in physical activity programs on adult physical activity in Meade County, Kentucky. Meade 
County is a unique community of families working together and supporting each other. In recent years, the community has placed great emphasis on increasing physical activity in children through programs at the MAC and through the school system. Although these efforts have largely focused on children, their effects in increasing child physical activity levels have somewhat "trickled-down" to influence physical activity in parents as well, due to the close-knit, family-centered social environment specific to this community. Only limited resources have been invested into increasing community opportunities for adult and family physical activity. While children are active in MAC programs conducted in borrowed spaces, this lack of community spaces for families to be physically active together impedes the potential effect on parents.

These results have important implications for health promotion. Rural populations experience high rates of obesity and physical inactivity, with limited public health resources to address these issues. These results indicate that the benefits of a communitybased child-targeted physical activity initiative can spill over to parents in rural, familyoriented communities. However, a community space for parents and children to be physically active together is a critical enabling factor. The next chapter will discuss these findings in regards to the four research questions that guided this study, highlighting variables that impacted the outcomes. Results from the present study will be compared to existing literature. In addition, study limitations and suggestions for future research will be offered. 


\section{CHAPTER V \\ DISCUSSION}

\section{Introduction}

The purpose of this study was to explore the influence of child participation in physical activity programs on parent physical activity behaviors within a rural Kentucky community. In 2008, a coalition of community leaders and parents sought to increase access to physical activity opportunities for residents of Meade County, Kentucky. To date, the Meade Activity Center (MAC) has implemented a variety of year-round programs for children conducted at borrowed spaces from local schools. The MAC utilized the strategy to first engage children as a way to extend behavior change to other members of the community. Little is known about child influence on parent health decisions and behaviors. This study contributes to the limited literature concerning the interpersonal influences between family members in health behaviors.

Focus groups and individual interviews were conducted with 21 parents of MAC program participants. All focus groups and individual interviews were audio recorded and transcribed verbatim. Using a grounded theoretical approach, data were analyzed through open, axial, and selective coding processes in QSR NVivo 10. Four main conceptual findings resulted from this study: "Family is Central to Community Identity," "Increased Community Priority in Physical Activity," "Children Influence Parent Physical Activity," and "Barriers to Parent Physical Activity," which are presented in chapter 4. 
In this chapter, the discussion of project findings is organized by the research questions that guided the study. Limitations of the study are identified and addressed. Recommendations for the MAC and similar projects in rural communities are provided. Finally, implications for future research are discussed.

\section{Discussion of Research Questions}

The findings in this study provide insight into the influence of child participation in MAC physical activity programs on parent physical activity in Meade County, KY. The four research questions that guided this exploratory study were as follows:

Research Question 1: Do parents believe the MAC project has influenced their children's physical activity behaviors?

Research Question 2: Has the MAC project influenced adult physical activity behaviors?

Research Question 3: What is the influence on parent physical activity resulting from child participation in MAC physical activity programs?

Research Question 4: What are the barriers and enabling factors to participation in adult MAC physical activity programs?

Results from the study are discussed in context of these research questions, and connected with the current literature.

\section{Research Question 1}

The first guiding question asked, "Do parents believe the MAC project has influenced their children's physical activity behaviors?” Throughout focus groups and individual interviews, parents spoke at length about the impact of MAC programming on their children's physical activity. Previous measures evaluating MAC programs revealed 
improved physical activity levels and health outcomes among child participants (King \& Rice, 2014). Through the present study, parents provided information that expands on these results.

Children participated in physical activity on a more consistent basis through their involvement with the MAC. Parents of REC League Afterschool Program participants reported increased levels of physical activity in children, as they were engaged in structured physical activity through daily programming. Similar after school programs have proven to be effective interventions to increase physical activity levels in children (Beets, Beighle, Erwin, \& Huberty, 2009; Coleman, Geller, Rosenkranz, \& Dzewaltowski, 2008; Huberty, Balluff, Beighle, Berg, \& Sun, 2009).

In addition to increased activity levels, parents reported other important benefits for children. MAC programming options allow children in the community the opportunity to try new physical activities. Through the affordability and short duration of MAC sport programs, children are exposed to a variety of sport programs and may try multiple options without making long-term commitments or incurring great expenses to participate. This allows for Meade County children to experience the concept of "sport sampling," where children participate in a variety of different sport programs as opposed to only partaking or specializing in a single sport (Cote, Baker, \& Abernethy, 2007). The literature suggests that sampling a variety of sport activities provides children with diverse socialization experiences with peers and adults (i.e. coaches) that shape development (Bridge \& Toms, 2013; Cote et al., 2007; Coté, Horton, MacDonald, \& Wilkes, 2009). 
With this in mind, it is no coincidence that participants also commented on the social growth they see in their children through involvement in team sports. Children established friendships through the MAC sport programs, which was particularly helpful for newcomers with few established connections to the community. In addition to improved physical activity levels, child MAC participation may result in additional health benefits such as increased social integration. Child participation in structured out-ofschool time, such as sport activities, has been linked with positive youth development (Brunelle, Danish, \& Forneris, 2007; Eime, Young, Harvey, Charity, \& Payne, 2013; Larson, Hansen, \& Moneta, 2006; Zarnett, Coyte, Nauenberg, Doran, \& Laporte, 2009). Overall, parents reported increased physical activity and personal development in their children as a result of MAC participation.

\section{Research Question 2}

The second research question examined, "Has the MAC project influenced adult physical activity behaviors?" Overall, the MAC project has served as a catalyst for community change, resulting in an increased awareness of the importance of leading physically active lifestyles. Many individuals and organizations within the community have contributed to the success of the MAC. Parents have volunteered to serve as coaches for child sport programs. Numerous physical activity programs have been implemented in borrowed locations throughout the community including schools, churches, and land donated to MAC. The support that the MAC receives from community stakeholders and partners is critical to the success and reach of the program.

This increased awareness has resulted in new opportunities for community adults, children, and families to be physically active. Participants indicated that investments 
have been made to upkeep and develop community parks, walking trails, and other public spaces to enhance opportunities for Meade County residents to live active lives. The field of active living research indicates that increasing access to such community spaces is a proven and highly effective strategy to increase physical activity and reduce obesity in communities (Evenson, Sallis, Handy, Bell, \& Brennan, 2012; Sallis et al., 2006; Task Force on Community Preventive Services, 2002). In terms of economic impact, Wang et al. (2005) found that for every $\$ 1$ spent on community trails, there was a $\$ 3$ savings in medical costs.

In addition, the MAC initiative has led to new family and adult fitness events and programs in the community. While the MAC does currently offer some adult-only programming, these are not well promoted. Only 6 of the participants in this study indicated that they had participated in any of the MAC adult programs (4 participated in a $5 \mathrm{k}, 1$ swimming, and 1 zumba). The MAC has hosted or partnered with local organizations on community run/walk races and cycling events. Participants in this study enjoyed these events and many reported participating in these with their children as a family.

Other new adult physical activity opportunities include group fitness classes held at the community library and a new CrossFit facility. Yet, study participants were not engaged in these programs either due to logistical or financial considerations. While the fitness classes offered at the library were free, they were often inconsistent, and offered at limited times. Participants also found them unappealing since they were conducted in borrowed space at the library. Membership at the new CrossFit facility was more than $\$ 100$ per month per person. MAC memberships are significantly less than this as family 
memberships range from $\$ 40$ - $\$ 80$ per month or less, depending on membership type and financial assistance eligibility. New family fitness initiatives through the school system have also provided new outlets for adults to engage in physical activity.

Overall, the MAC project has brought an increased awareness of the importance of physical activity to the entire community of Meade County, including adults. However, there is still a lack of programming and accessible spaces for adult physical activity. This limits the impact of the MAC initiatives on parents in the community.

\section{Research Question 3}

The third central question asked, "What is the influence on parent physical activity resulting from child participation in MAC physical activity programs?" There are both direct and indirect effects of child participation in MAC programs. Directly, children often practice MAC sports at home. For example, children enrolled in respective MAC programs may dribble a basketball in the driveway, kick a soccer ball in the backyard, or practice taekwondo in the living room. When children are introduced to new and different sports, they share these experiences and engage parents in these activities. Parents support and encourage their children to be physically active, and are eager to engage in joint activities with their children.

Participants described many instances of engaging in physical activity with their children. Participant accounts of family exercise revealed a bidirectional influence of physical activity initiation. The majority of parents categorized the initiation of parentchild joint physical activity as a "50/50" relationship. Younger children initiated and asked parents to engage in physical activity with them more frequently than adolescents. Similarly, adolescents were less likely to engage in joint or family activities. 
The MAC project has resulted in more active children and adults within the Meade County community. However, child participation in MAC programming places greater demands on parent schedules. Many hours are spent sitting in local school gyms and other community venues watching children play sports. Transporting children to and from MAC activities also presents further time constraints on parents. More consideration should be given to accommodate parent schedules and promote MAC adult program offerings. Conducting adult physical activity programs while child activities are taking place may result in higher rates of adult participation in MAC fitness programs.

\section{Research Question 4}

The final overarching question probed, "What are the barriers and enabling factors to participation in adult MAC physical activity programs?" Study results revealed many barriers to parent physical activity in the community. These barriers, along with enabling factors, are discussed within the context of the social ecological model (Sallis, Owen, \& Fisher, 2008).

At the community level, there are few available and accessible physical activity opportunities and programs for adults. Participants described current available adult programs as expensive, inconsistent, and seasonal or dependent on weather. These findings are consistent with other studies that highlight the lack of access to facilities where one can be physically active as a significant barrier to adult physical activity in rural communities (Calise et al., 2013; Casey et al., 2008; Humpel, Owen, \& Leslie, 2002; Huston et al., 2003; Lovasi et al., 2009; McCormack \& Shiell, 2011; Powell et al., 2006). This lack of facilities and spaces for physical activity is a significant barrier to adult physical activity in Meade County. 
At the organizational level, the MAC currently provides very limited adult physical activity offerings, which were variable and poorly promoted. Child MAC programs were promoted through the school system, with materials publicizing child offerings sent home with students. However, study participants had a difficult time identifying MAC adult programs. The MAC website was described as "confusing," "unclear," and "outdated," and parents acknowledged difficulties in finding information listing adult programs. Parents were also unsure of the benefits afforded by MAC membership, particularly for adults who were included in family memberships. Parents did report engaging in family MAC activities such as run/walk races and swimming. However, there is a clear need for more MAC adult programs which are promoted to adults in the community.

In addition to the limited accessibility of adult physical activity programs, other barriers and enabling factors were present at the interpersonal level. Families within Meade County often exercise and are active together, with children sometimes leading and initiating these efforts. However, participants reported parenting responsibilities and related time constraints as further barriers to physical activity. Scheduling constraints are a commonly reported barrier for parents (Mailey et al., 2014). Parents of small children identified lack of available childcare as an additional obstacle, similar to the findings of Hamilton and White (2010) which highlighted instrumental support needs to allow for time for parent physical activity. Thus, access to exercise facilities with available childcare may increase parent physical activity participation.

Parents also identified scheduling challenges incurred by the current MAC model of programming. As child activities are conducted in borrowed community spaces, this 
leads to inconsistent times and locations for programming. Time is quickly filled by the responsibility of transporting children to MAC activities and watching them practice or play their sport on game days. This problem proliferates when parents have multiple children engaged in MAC programming at various times and differing venues. The creation of a centralized space for MAC child and adult programs, with available childcare, would mitigate most of the ecological barriers to physical activity faced by adults in Meade County.

\section{Limitations of the Study}

This project adds significant contributions to the available literature examining the child influence on parent physical activity behaviors, as well as barriers and enabling factors affecting adult physical activity in rural communities. Findings from this study provide a framework for further research in these areas. However, this study had several limitations that should be considered.

Principally, results from this study are specific to this community, which should be considered when transferring findings to other populations. The population and initiative examined in this dissertation were extension of a multi-year, community-based physical activity health promotion intervention, in which other researchers from the University of Louisville have worked in partnership with and in the community. Other populations may not have access to the funding opportunities, program design, and implementation guidance as afforded when working with a university partner.

As previously discussed, the community of Meade County, KY is exceptionally family-oriented. This study explored the influence of children on parent physical activity. The focus on family within the community as well as the importance of children to adult 
socialization also limits generalizability. While other small communities may have similar features stereotypical of rural residency, these characteristics may not be present in all rural populations.

Another potential limitation concerns the sampling methodology used for this study. Participant recruitment and enrollment relied on a convenience sample of volunteers who responded to emails, flyers, and recruitment conversations with the researcher. As discussed in chapter 3, the researcher encountered many recruitment challenges, particularly in the recruitment of males. When generalizing these findings to parents in other communities, it is important to keep in mind that only one participant was male. Thus, the experiences of fathers in the community may differ from what was reported in the data.

In addition, all participants were married, and $62 \%$ held a college degree, much higher than the county rate of $12 \%$ (United States Census Bureau, 2014). The experiences reported by this sample may not be representative of that of all parents in the community. Data collection also relied on participant self-reported behaviors, not actual observed physical activities. It is also possible that these individuals may be more involved and invested in the MAC than the population of all MAC parents. In these regards, respondent bias is possible if these individuals supplied answers motivated by their desires for MAC programs to continue and the knowledge of the long-term goal to implement of a physical MAC building.

It is also important to note that one researcher conducted the majority of the data collection and analysis processes for this project, which allows for the possibility that researcher bias influenced study outcomes. While a four-person faculty committee guided 
this dissertation study, the researcher was the primary person responsible for protocol development, facilitation of interviews and focus groups, and analysis of data. As indicated in chapter 3, several provisions were implemented to mitigate potential researcher bias effects, assuring credibility and confirmability of the findings.

\section{Conclusions and Implications}

Although there were several limitations that affect the generalizability of these findings to other populations, this study serves as an important step in addressing gaps in the literature pertaining to interpersonal health behavioral influences between family members. MAC program effects in increasing child physical activity levels have somewhat "trickled-down" to influence physical activity in parents as well due to the close-knit, family-centered social environment specific to this community. Parents and children encouraged and motivated each other to be physically active, though younger children initiated joint physical activity more often than adolescents. Barriers to adult physical activity, including a lack of community spaces for families to be physically active together, were identified.

These findings indicate a bidirectional influence between parent and child physical activity behaviors and the need for community recreational facilities where both children and adults can be physically active together. This study aids in identifying predictors and enabling factors regarding the influence of child physical activity levels on parent physical activity behaviors. Study findings highlight the need for further research into the relationship between child interventions and parent health behaviors and outcomes. This study provides important implications for the current and future efforts of the MAC as well as the field of health promotion and behavioral sciences. 


\section{Implications for the MAC}

As this study was conducted within a unique community, the results have several important implications specific to the MAC. Although the MAC recently broke ground for a new Health and Wellness Facility, funding is still needed to support the completion and maintenance of a physical building. The organization also needs sustainable funding to continue to offer current and implement new programs and increase capacity for the number of Meade County residents the MAC serves, particularly those on a sliding fee scale. The results from this study were shared with Aaron Greenwell, Executive Director of the Meade Activity Center. This information may prove invaluable as the MAC pursues important next steps in facility construction and the implementation of new programs.

Several programming recommendations were made as a result of this study. Participants were eager for more diverse and abundant physical activity offerings in the community. Current MAC adult program offerings should be expanded immediately. These programs should be promoted to adults in the community through multiple communication channels including regularly updating the MAC website, social media accounts, and distributing information on adult programming through the school system. Clear guidelines pertaining to adult membership (family or individual) should be provided on the MAC website and promotional materials, including details about sliding scale membership fees.

In the future, when the physical building for the MAC Health and Wellness Facility is operational, several considerations should be given to the structure of both adult and child program offerings. Time constraints related to childcare and child activity 
schedules were identified as major barriers to parent physical activity. There is a need for a facility where parents can exercise while children are in their sport practice. Offering adult physical activity programs while child activities are taking place may result in higher rates of adult participation in MAC fitness programs. It is also recommended that this facility provide childcare for parents with smaller children who may not be old enough to participate in MAC sport programs. These strategies may ease the scheduling demands and time constraints of parents and facilitate increased activity levels.

The results from this study may also aid the MAC in pursuing and securing additional funding sources to expand and sustain programming and facilities. This project indicates that the benefits of the MAC extend beyond community children. The MAC initiative has been a stimulus for community change, engaging families in physical activity. This extended reach to other community members demonstrates a significant return on investment. The MAC may reach out to local firms and employers for support as they benefit from a healthy and productive workforce comprised of physically active adults.

In addition, this baseline knowledge of barriers and enabling factors that influence parent physical activity could strengthen future grant submissions for funds aimed at adult programming. In the past, the MAC has benefitted from grant funds for programming concerning childhood obesity and physical activity. There may be additional funding opportunities for projects that investigate the implementation and effectiveness of adult or family-based physical activity initiatives in rural communities.

\section{Implications for Practice and Future Research}


These results have important implications for health promotion. Rural populations experience high rates of obesity and physical activity, with limited public health resources to address these issues. Results indicate that the benefits of a community-based child physical activity intervention can trickle over to impact physical activity behaviors of parents. As rural communities continue to struggle with high rates of obesity and physical inactivity in adults and children, the MAC project offers several suggestions for developing future programs in similar communities. This study provides evidence that the benefits of a community-based child-focused physical activity initiative can impact parents in rural, family-oriented communities. Interventions that engage both children and parents in community spaces and opportunities for joint physical activity may be most effective in promoting adult physical activity in rural communities.

This study examined a topic with very little existing literature. While the successes and findings from the MAC project serve as an important case study, further research is needed to examine the effects of child-focused interventions on parental health behaviors and outcomes. This dissertation was an extension of a multi-year community-based physical activity health promotion intervention. Original project design and measures considered changes in child physical activity behaviors and health outcomes and coalition effectiveness, as dictated by the original funding agency. As the MAC moves forward, the results from this study allow for further research in several areas. Findings can inform the development of a follow-up quantitative survey to assess the influence of child participation in MAC program on a larger sample of community parents. As the MAC opens the Health and Wellness Facility, additional investigations may be conducted to evaluate the implementation and impact of an adult physical activity 
facility and programming. Changes in adult physical activity levels should be tracked longitudinally, measured at baseline before the implementation of the MAC facility. As other communities adopt such child-targeted physical activity programs, future studies should consider the impact on parents from inception. The MAC model could be replicated in other rural and underserved settings. In addition to tracking changes in child health behaviors and health outcomes, parent physical activity levels, BMI, or other quantitative measures should also be assessed at baseline and followed longitudinally to determine the full impact of these interventions.

Results from this study highlight the need for further exploration in to the relationship between child-focused interventions and parent health behaviors. High rates of obesity and physical inactivity in both child and adult populations persist with limited resources to address these issues. These bidirectional influences between family members may further stretch the return on investment and public health benefits of communitybased child physical activity interventions. 


\section{REFERENCES}

Albright, C. L., Maddock, J. E., \& Nigg, C. R. (2006). Physical activity before pregnancy and following childbirth in a multiethnic sample of healthy women in Hawaii. Women \& Health, 42(3), 95-110. doi: 10.1300/J013v42n03_06

Alderman, B. L., Benham-Deal, T. B., \& Jenkins, J. M. (2010). Change in parental influence on children's physical activity over time. J Phys Act Health, 7(1), 60-67.

Anderson, C. B., Hughes, S. O., \& Fuemmeler, B. F. (2009). Parent-child attitude congruence on type and intensity of physical activity: Testing multiple mediators of sedentary behavior in older children. Health Psychol, 28(4), 428-438. doi: $10.1037 / \mathrm{a} 0014522$

Auchincloss, A. H., \& Hadden, W. (2002). The health effects of rural-urban residence and concentrated poverty. J Rural Health, 18(2), 319-336.

Auld, G. W., Diker, A., Bock, M. A., Boushey, C. J., Bruhn, C. M., Cluskey, M., .. . Zaghloul, S. (2007). Development of a decision tree to determine appropriateness of NVivo in analyzing qualitative data sets. J Nutr Educ Behav, 39(1), 37-47. doi: 10.1016/j.jneb.2006.09.006

Bandura, A. (1986). Social foundations of thought and action: A social cognitive theory. Englewood Cliffs, N.J.: Prentice-Hall.

Bandura, A. (1989). Social cognitive theory. In R. Vasta (Ed.), Annals of child development (Vol. 6, pp. 1-60). Greenwich, CT: JAI Press. 
Bandura, A. (1997). Self-efficacy: The exercise of control. New York: Freeman.

Bauer, K. W., Nelson, M. C., Boutelle, K. N., \& Neumark-Sztainer, D. (2008). Parental influences on adolescents' physical activity and sedentary behavior: Longitudinal findings from Project EAT-II. Int J Behav Nutr Phys Act, 5, 12. doi:

$10.1186 / 1479-5868-5-12$

Bauer, K. W., Neumark-Sztainer, D., Fulkerson, J. A., Hannan, P. J., \& Story, M. (2011). Familial correlates of adolescent girls' physical activity, television use, dietary intake, weight, and body composition. Int J Behav Nutr Phys Act, 8, 25. doi: $10.1186 / 1479-5868-8-25$

Bauman, A. E., Sallis, J. F., Dzewaltowski, D. A., \& Owen, N. (2002). Toward a better understanding of the influences on physical activity. Am J Prev Med, 23(2S), 514.

Beets, M. W., Beighle, A., Erwin, H. E., \& Huberty, J. L. (2009). After-school program impact on physical activity and fitness: A meta-analysis. Am J Prev Med, 36(6), 527-537. doi: 10.1016/j.amepre.2009.01.033

Befort, C. A., Nazir, N., \& Perri, M. G. (2012). Prevalence of obesity among adults from rural and urban areas of the United States: Findings from NHANES (2005-2008). J Rural Health, 28(4), 392-397. doi: 10.1111/j.1748-0361.2012.00411.x

Belch, M. A., Krentler, K. A., \& Willis-Flurry, L. A. (2005). Teen internet mavens: Influence in family decision making. Journal of Business Research, 58(5), 569575. 
Bellows-Riecken, K. H., \& Rhodes, R. E. (2008). A birth of inactivity? A review of physical activity and parenthood. Prev Med, 46(2), 99-110. doi: http://dx.doi.org/10.1016/j.ypmed.2007.08.003

Blair, S. N., \& Brodney, S. (1999). Effects of physical inactivity and obesity on morbidity and mortality: Current evidence and research issues. Med Sci Sports Exerc, 31(11 Suppl), S646-662.

Blumer, H. (1969). Symbolic interactionism: Perspective and method. Los Angeles, CA: University of California Press.

Bridge, M. W., \& Toms, M. R. (2013). The specialising or sampling debate: A retrospective analysis of adolescent sports participation in the UK. J Sports Sci, 31(1), 87-96. doi: 10.1080/02640414.2012.721560

Brockman, R., Jago, R., Fox, K. R., Thompson, J. L., Cartwright, K., \& Page, A. S. (2009). "Get off the sofa and go and play": Family and socioeconomic influences on the physical activity of 10-11 year old children. BMC Public Health, 9, 253. doi: 10.1186/1471-2458-9-253

Brown, S. A., \& Venkatesh, V. (2005). Model of adoption of technology in households: A baseline model test and extension incorporating household life cycle. MIS quarterly, 399-426.

Brunelle, J., Danish, S. J., \& Forneris, T. (2007). The impact of a sport-based life skill program on adolescent prosocial values. Applied Developmental Science, 11, 4355. 
Buckler, A., \& Servies, T. (2013). Behavioral counseling interventions to promote a healthful diet and physical activity for cardiovascular disease prevention in adults. Am Fam Physician, 87(12), 869-870.

Butera, K. J. (2006). Manhunt: The challenge of enticing men to participate in a study on friendship. Qualitative Inquiry, 12(6), 1262-1282. doi:

$10.1177 / 1077800406288634$

Calise, T. V., Heeren, T., DeJong, W., Dumith, S. C., \& Kohl, H. W. (2013). Do neighborhoods make people active, or do people make active neighborhoods? Evidence from a planned community in Austin, Texas. Prev Chronic Dis, 10, E102. doi: $10.5888 / \mathrm{pcd} 10.120119$

Casey, A. A., Elliott, M., Glanz, K., Haire-Joshu, D., Lovegreen, S. L., Saelens, B. E., . . . Brownson, R. C. (2008). Impact of the food environment and physical activity environment on behaviors and weight status in rural U.S. communities. Prev Med, 47(6), 600-604. doi: 10.1016/j.ypmed.2008.10.001

Centers for Disease Control and Prevention. (1997). Principles of community engagement. Atlanta, GA: CDC/ATSDR Committee on Community Engagement.

Centers for Disease Control and Prevention. (2001). A report on recommendations of the Task Force on Community Preventive Services. MMWR Recomm Rep, 50(RR18), $1-16$.

Centers for Disease Control and Prevention. (2011). BRFSS Behavioral Risk Factor Sruveillance System: Prevalence and Trend Data, U.S. Physical Activity Trends by State Retrieved March 3, 2014, from http://www.cdc.gov/brfss/ 
Charmaz, K. (2006). Constructing grounded theory: A practical guide through qualitative analysis. Thousand Oaks, CA: Sage.

Cleland, C. L., Tully, M. A., Kee, F., \& Cupples, M. E. (2012). The effectiveness of physical activity interventions in socio-economically disadvantaged communities: A systematic review. Prev Med, 54(6), 371-380. doi:

10.1016/j.ypmed.2012.04.004

Cleland, V., Granados, A., Crawford, D., Winzenberg, T., \& Ball, K. (2013). Effectiveness of interventions to promote physical activity among socioeconomically disadvantaged women: A systematic review and metaanalysis. Obes Rev, 14(3), 197-212. doi: 10.1111/j.1467-789X.2012.01058.x

Coffield, E., Nihiser, A. J., Sherry, B., \& Economos, C. D. (2015). Shape Up Somerville: Change in parent body mass indexes during a child-targeted, community-based environmental change intervention. American Journal of Public Health, 105(2), e83-e89. doi: 10.2105/AJPH.2014.302361

Colditz, G. A. (1999). Economic costs of obesity and inactivity. Med Sci Sports Exerc, 31(11 Suppl), S663-667.

Coleman, K. J., Geller, K. S., Rosenkranz, R. R., \& Dzewaltowski, D. A. (2008). Physical activity and healthy eating in the after-school environment. Journal of School Health, 78(12), 633-640.

Cook, W. L. (2001). Interpersonal influence in family systems: A social relations model analysis. Child Development, 72(4), 1179-1197. 
Correa, T. (2014). Bottom-up technology transmission within families: Exploring how youths influence their parents' digital media use with dyadic data. Journal of Communication, 64(1), 103-124. doi: 10.1111/jcom.12067

Cote, J., Baker, J., \& Abernethy, B. (2007). Practice and play in the development of sport expertise. In G. Tenenbaum \& R. C. Eklun (Eds.), Handbook of sport psychology (pp. 184-202). Hoboken, NJ: Wiley.

Coté, J., Horton, S., MacDonald, D., \& Wilkes, S. (2009). The benefits of sampling sports during childhood. Physical \& Health Education Journal, 74(4), 6.

Cottrell, R., McKenzie, J., \& James, F. (2010). Health promotion and education research methods: Using the five chapter thesis/dissertation model. Sudbury, MA: Jones and Bartlett.

Craig, C. L., Cameron, C., \& Tudor-Locke, C. (2013). Relationship between parent and child pedometer-determined physical activity: A sub-study of the CANPLAY surveillance study. Int J Behav Nutr Phys Act, 10, 8. doi: 10.1186/1479-5868-10-8

Creswell, J. W. (2013). Qualitative inquiry and research design: Choosing among five approaches (3rd ed.). Thousand Oaks, CA: Sage.

Creswell, J. W. (2014). Research design: Qualitative, quantitative, and mixed methods approaches (4th ed.). Thousand Oaks, CA: Sage.

De Mol, J., \& Buysse, A. (2008). The phenomenology of children's influence on parents. Journal of Family Therapy, 30(2), 163-193. doi: 10.1111/j.14676427.2008.00424.x 
DiLorenzo, T. M., Stucky-Ropp, R. C., Vander Wal, J. S., \& Gotham, H. J. (1998). Determinants of exercise among children. II. A longitudinal analysis. Prev Med, 27(3), 470-477. doi: 10.1006/pmed.1998.0307

Dowda, M., Pfeiffer, K. A., Brown, W. H., Mitchell, J. A., Byun, W., \& Pate, R. R. (2011). Parental and environmental correlates of physical activity of children attending preschool. Arch Pediatr Adolesc Med, 165(10), 939-944. doi: 10.1001/archpediatrics.2011.84

Eakin, E. G., Glasgow, R. E., \& Riley, K. M. (2000). Review of primary care-based physical activity intervention studies: Effectiveness and implications for practice and future research. J Fam Pract, 49(2), 158-168.

Eberhardt, M. S., \& Pamuk, E. R. (2004). The importance of place of residence: Examining health in rural and nonrural areas. Am J Public Health, 94(10), 16821686.

Economic Research Service. (2010). Rural America at a Glance. Washington, DC: USDA.

Eime, R. M., Young, J. A., Harvey, J. T., Charity, M. J., \& Payne, W. R. (2013). A systematic review of the psychological and social benefits of participation in sport for children and adolescents: Informing development of a conceptual model of health through sport. Int J Behav Nutr Phys Act, 10, 98. doi: 10.1186/1479-5868$10-98$

Etcheverry, P. E., \& Agnew, C. R. (2008). Romantic partner and friend influences on young adult cigarette smoking: Comparing close others' smoking and injunctive 
norms over time. Psychol Addict Behav, 22(3), 313-325. doi: 10.1037/0893164X.22.3.313

Evenson, K. R., Sallis, J. F., Handy, S. L., Bell, R., \& Brennan, L. K. (2012). Evaluation of physical projects and policies from the Active Living by Design partnerships. Am J Prev Med, 43(5 Suppl 4), S309-319. doi: 10.1016/j.amepre.2012.06.024

Everson-Hock, E. S., Johnson, M., Jones, R., Woods, H. B., Goyder, E., Payne, N., \& Chilcott, J. (2013). Community-based dietary and physical activity interventions in low socioeconomic groups in the UK: A mixed methods systematic review. Prev Med, 56(5), 265-272. doi: 10.1016/j.ypmed.2013.02.023

Frieden, T. R. (2010). A framework for public health action: The health impact pyramid. Am J Public Health, 100(4), 590-595. doi: 10.2105/AJPH.2009.185652

Gillham, B. (2000). The research interview. New York, NY: Contiuum.

Glaser, B. G., \& Strauss, A. L. (1965). Awareness of dying. Chicago: Aldine.

Glaser, B. G., \& Strauss, A. L. (1967). The discovery of grounded theory. Chicago: Aldine.

Glaser, B. G., \& Strauss, A. L. (1968). Time for dying. Chicago: Aldine.

Goetzel, R. Z., Hawkins, K., Ozminkowski, R. J., \& Wang, S. (2003). The health and productivity cost burden of the "top 10" physical and mental health conditions affecting six large U.S. employers in 1999. J Occup Environ Med, 45(1), 5-14.

Götze, E., Prange, C., \& Uhrovska, I. (2009). Children's impact on innovation decision making: A diary study. European Journal of Marketing, 43(1-2), 1-2.

Green, J., \& Thorogood, N. (2009). Qualitative methods for health research (2nd ed.). Thousand Oaks, CA: Sage. 
Gruber, K. J., \& Haldeman, L. A. (2009). Using the family to combat childhood and adult obesity. Prev Chronic Dis, 6(3), A106.

Hamilton, K., \& White, K. M. (2010). Parental physical activity: Exploring the role of social support. Am J Health Behav, 34(5), 573-584.

Hartley, D. (2004). Rural health disparities, population health, and rural culture. Am J Public Health, 94(10), 1675-1678.

Heim, S., Bauer, K. W., Stang, J., \& Ireland, M. (2011). Can a community-based intervention improve the home food environment? Parental perspectives of the influence of the delicious and nutritious garden. J Nutr Educ Behav, 43(2), 130134. doi: 10.1016/j.jneb.2010.01.003

Hennessy, E., Hughes, S. O., Goldberg, J. P., Hyatt, R. R., \& Economos, C. D. (2010). Parent-child interactions and objectively measured child physical activity: A cross-sectional study. Int J Behav Nutr Phys Act, 7, 71. doi: 10.1186/1479-58687-71

Hillsdon, M., Thorogood, M., Anstiss, T., \& Morris, J. (1995). Randomised controlled trials of physical activity promotion in free living populations: A review. $J$ Epidemiol Community Health, 49(5), 448-453.

Huberty, J., Balluff, M., Beighle, A., Berg, K., \& Sun, J. (2009). Club Possible: Feasibility of a community collaborative after-school physical activity program for children ages 5-12 years. Journal of Park \& Recreation Administration, 27(2).

Hull, E. E., Rofey, D. L., Robertson, R. J., Nagle, E. F., Otto, A. D., \& Aaron, D. J. (2010). Influence of marriage and parenthood on physical activity: A 2-year prospective analysis. Journal of Physical Activity \& Health, 7(5), 577-583. 
Humpel, N., Owen, N., \& Leslie, E. (2002). Environmental factors associated with adults' participation in physical activity: A review. Am J Prev Med, 22(3), 188-199.

Huston, S. L., Evenson, K. R., Bors, P., \& Gizlice, Z. (2003). Neighborhood environment, access to places for activity, and leisure-time physical activity in a diverse North Carolina population. Am J Health Promot, 18(1), 58-69.

Isgor, Z., Powell, L. M., \& Wang, Y. (2013). Multivariable analysis of the association between fathers' and youths' physical activity in the United States. BMC Public Health, 13, 1075. doi: 10.1186/1471-2458-13-1075

Jenkins, R. L. (1979). The influence of children in family decision-making: Parents' perceptions In W. L. Wilkie (Ed.), Advances in consumer research (Vol. 6, pp. 413-418). Ann Arbor, MI: Association for Consumer Research.

Kahn, E. B., Ramsey, L. T., Brownson, R. C., Heath, G. W., Howze, E. H., Powell, K. E., ... Corso, P. (2002). The effectiveness of interventions to increase physical activity: A systematic review. Am J Prev Med, 22(4, Supplement 1), 73-107. doi: http://dx.doi.org/10.1016/S0749-3797(02)00434-8

Kellou, N., Sandalinas, F., Copin, N., \& Simon, C. (2014). Prevention of unhealthy weight in children by promoting physical activity using a socio-ecological approach: What can we learn from intervention studies? Diabetes Metab. 40(4), 258-271. doi: 10.1016/j.diabet.2014.01.002

King, K. M., \& Rice, J. (2014). Final Report (3rd Year) of Meade Activity Center Project. Unpublished Evaluation Report.

Krueger, R. A., \& Casey, M. A. (2009). Focus groups: A practical guide for applied research (4th ed.). San Francisco, CA: Sage. 
Langille, J. L., \& Rodgers, W. M. (2010). Exploring the influence of a social ecological model on school-based physical activity. Health Educ Behav, 37(6), 879-894. doi: $10.1177 / 1090198110367877$

Larson, R. W., Hansen, D. M., \& Moneta, G. (2006). Differing profiles of developmental experiences across types of organized youth activities. Dev Psychol, 42(5), 849863. doi: $10.1037 / 0012-1649.42 .5 .849$

Lattimore, D., Griffin, S. F., Wilcox, S., Rheaume, C., Dowdy, D. M., Leviton, L. C., \& Ory, M. G. (2010). Understanding the challenges encountered and adaptations made by community organizations in translation of evidence-based behavior change physical activity interventions: A qualitative study. Am J Health Promot, 24(6), 427-434. doi: 10.4278/ajhp.081024-QUAL-252

Lee, I. M., Shiroma, E. J., Lobelo, F., Puska, P., Blair, S. N., \& Katzmarzyk, P. T. (2012). Effect of physical inactivity on major non-communicable diseases worldwide: An analysis of burden of disease and life expectancy. Lancet, 380(9838), 219-229. doi: 10.1016/s0140-6736(12)61031-9

Leonardi-Bee, J., Jere, M. L., \& Britton, J. (2011). Exposure to parental and sibling smoking and the risk of smoking uptake in childhood and adolescence: A systematic review and meta-analysis. Thorax, 66(10), 847-855. doi: 10.1136/thx.2010.153379

Lincoln, Y. S., \& Guba, E. G. (1985). Naturalistic inquiriy. Newbury Park, CA: Sage. Loeppke, R., Taitel, M., Richling, D., Parry, T., Kessler, R. C., Hymel, P., \& Konicki, D. (2007). Health and productivity as a business strategy. J Occup Environ Med, 49(7), 712-721. doi: 10.1097/JOM.0b013e318133a4be 
Lovasi, G. S., Hutson, M. A., Guerra, M., \& Neckerman, K. M. (2009). Built environments and obesity in disadvantaged populations. Epidemiol Rev, 31, 7-20. doi: 10.1093/epirev/mxp005

Madsen, K. A., McCulloch, C. E., \& Crawford, P. B. (2009). Parent modeling: Perceptions of parents' physical activity predict girls' activity throughout adolescence. J Pediatr, 154(2), 278-283. doi: 10.1016/j.jpeds.2008.07.044

Mailey, E. L., Huberty, J., Dinkel, D., \& McAuley, E. (2014). Physical activity barriers and facilitators among working mothers and fathers. BMC Public Health, 14, 657. doi: $10.1186 / 1471-2458-14-657$

Martin, S. L., Kirkner, G. J., Mayo, K., Matthews, C. E., Durstine, J. L., \& Hebert, J. R. (2005). Urban, rural, and regional variations in physical activity. J Rural Health, 21(3), 239-244.

McAlister, A. L., Perry, C. L., \& Parcel, G. S. (2008). How individuals, environments, and health behaviors interact. In K. Glanz, B. K. Rimer \& K. Viswanath (Eds.), Health behavior and health education: Theory research, and practice (4th ed., pp. 169-188). San Francisco: Jossey-Bass.

McCormack, G. R., \& Shiell, A. (2011). In search of causality: A systematic review of the relationship between the built environment and physical activity among adults. Int J Behav Nutr Phys Act, 8, 125. doi: 10.1186/1479-5868-8-125

McIntyre, C. A., \& Rhodes, R. E. (2009). Correlates of leisure-time physical activity during transitions to motherhood. Women \& Health, 49(1), 66-83. doi: $10.1080 / 03630240802690853$ 
McLeroy, K. R., Bibeau, D., Steckler, A., \& Glanz, K. (1988). An ecological perspective on health promotion programs. Health Educ Q, 15(4), 351-377.

McMinn, A. M., van Sluijs, E. M., Nightingale, C. M., Griffin, S. J., Cook, D. G., Owen, C. G., ... Whincup, P. H. (2011). Family and home correlates of children's physical activity in a multi-ethnic population: The cross-sectional Child Heart and Health Study in England (CHASE). Int J Behav Nutr Phys Act, 8, 11. doi: $10.1186 / 1479-5868-8-11$

Mehtala, M. A., Saakslahti, A. K., Inkinen, M. E., \& Poskiparta, M. E. (2014). A socioecological approach to physical activity interventions in childcare: A systematic review. Int J Behav Nutr Phys Act, 11, 22. doi: 10.1186/1479-5868-11-22

Mitchell, T., Haynes, K., Hall, N., Choong, W., \& Oven, K. (2008). The roles of children and youth in communicating disaster risk. Children Youth and Environments, $18(1), 254-279$.

Moore, L. L., Lombardi, D. A., White, M. J., Campbell, J. L., Oliveria, S. A., \& Ellison, R. C. (1991). Influence of parents' physical activity levels on activity levels of young children. J Pediatr, 118(2), 215-219.

Morgan, D. L. (1997). Focus groups as qualitative research (2nd ed.). Thousand Oaks, CA: Sage.

Moyer, V. A., \& Force, U. S. P. S. T. (2012). Behavioral counseling interventions to promote a healthful diet and physical activity for cardiovascular disease prevention in adults: U.S. Preventive Services Task Force recommendation statement. Ann Intern Med, 157(5), 367-371. doi: 10.7326/0003-4819-157-5201209040-00486 
National Highway Traffic Safety Administration. (1972). Evaluation of the effects of a seat belt education program among elementary school children in Louden County, Virginia. Washington, DC: Retrieved from http://ntl.bts.gov/lib/25000/25300/25328/DOT-HS-800-766.pdf.

National Institutes of Health. (1998). Clinical Guidelines on the Identification, Evaluation, and Treatment of Overweight and Obesity in Adults--The Evidence Report. National Institutes of Health. Obes Res, 6 Suppl 2, 51S-209S.

Ornelas, I. J., Perreira, K. M., \& Ayala, G. X. (2007). Parental influences on adolescent physical activity: A longitudinal study. Int J Behav Nutr Phys Act, 4, 3. doi: $10.1186 / 1479-5868-4-3$

Parks, S. E., Housemann, R. A., \& Brownson, R. C. (2003). Differential correlates of physical activity in urban and rural adults of various socioeconomic backgrounds in the United States. J Epidemiol Community Health, 57(1), 29-35.

Pate, R. R., Pratt, M., Blair, S. N., Haskell, W. L., Macera, C. A., Bouchard, C., .. King, A. C. (1995). Physical activity and public health: A recommendation from the Centers for Disease Control and Prevention and the American College of Sports Medicine. JAMA, 273(5), 402-407.

Patterson, P. D., Moore, C. G., Probst, J. C., \& Shinogle, J. A. (2004). Obesity and physical inactivity in rural America. $J$ Rural Health, 20(2), 151-159.

Patton, M. Q. (2002). Qualitative research and evaluation methods (3rd ed.). Thousand Oaks, CA: Sage.

Pavlish, C. P., \& Pharris, M. D. (2012). Community-based collaborative action research: A nursing approach. MA: Sudbury: Jones and Bartlett Learning. 
Pearson, N., Biddle, S. J., \& Gorely, T. (2009). Family correlates of fruit and vegetable consumption in children and adolescents: A systematic review. Public Health Nutr, 12(2), 267-283. doi: 10.1017/s1368980008002589

Powell, L. M., Slater, S., Chaloupka, F. J., \& Harper, D. (2006). Availability of physical activity-related facilities and neighborhood demographic and socioeconomic characteristics: A national study. Am J Public Health, 96(9), 1676-1680. doi: 10.2105/ajph.2005.065573

Rhodes, R. E., Blanchard, C. M., Benoit, C., Levy-Milne, R., Naylor, P. J., Symons Downs, D., \& Warburton, D. E. (2014). Physical activity and sedentary behavior across 12 months in cohort samples of couples without children, expecting their first child, and expecting their second child. J Behav Med, 37(3), 533-542. doi: $10.1007 / \mathrm{s} 10865-013-9508-7$

Rhodes, R. E., \& Dickau, L. (2013). Moderators of the intention-behaviour relationship in the physical activity domain: A systematic review. Br J Sports Med, 47(4), 215-225. doi: 10.1136/bjsports-2011-090411

Rimal, R. N., \& Flora, J. A. (1998). Bidirectional familial influences in dietary behavior test of a model of campaign influences. Human Communication Research, 24(4), 610-637. doi: 10.1111/j.1468-2958.1998.tb00433.x

Ritchie, J., Lewis, J., Elam, G., Tennant, R., \& Rahim, L. (2014). Designing and selecting samples. In J. Ritchie, J. Lewis, C. M. Nichols \& R. Ormston (Eds.), Qualitative research practice: A guide for social science students and researchers (2nd ed.). Thousand Oaks, CA: Sage. 
Robert Wood Johnson Foundation. (2014). County Health Rankings \& Roadmaps.

Retrieved from http://www.countyhealthrankings.org

Roux, L., Pratt, M., Tengs, T. O., Yore, M. M., Yanagawa, T. L., Van Den Bos, J., .. . Buchner, D. M. (2008). Cost effectiveness of community-based physical activity interventions. Am J Prev Med, 35(6), 578-588. doi: 10.1016/j.amepre.2008.06.040

Sallis, J. F., Cervero, R. B., Ascher, W., Henderson, K. A., Kraft, M. K., \& Kerr, J. (2006). An ecological approach to creating active living communities. Annu Rev Public Health, 27, 297-322. doi: 10.1146/annurev.publhealth.27.021405.102100

Sallis, J. F., \& Hovell, M. F. (1990). Determinants of exercise behavior. Exercise and Sport Sciences Reviews, 18(1), 307-330.

Sallis, J. F., Hovell, M. F., \& Hofstetter, C. R. (1992). Predictors of adoption and maintenance of vigorous physical activity in men and women. Prev Med, 21(2), $237-251$

Sallis, J. F., \& Nader, P. R. (1998). Family determinants of health behaviors. In D. S. Gochman (Eds.), Health behavior: Emerging research perspectives (pp. 107124). New York, NY: Springer.

Sallis, J. F., Owen, N., \& Fisher, E. B. (2008). Ecological models of health behavior. In K. Glanz, B. K. Rimer \& K. Viswanath (Eds.), Health behavior and health education (4 ed., pp. 465-485). San Francisco: Jossey-Bass.

Sallis, J. F., Prochaska, J. J., \& Taylor, W. C. (2000). A review of correlates of physical activity of children and adolescents. Medicine and Science in Sports and Exercise, 32(5), 963-975. 
Schoenborn, C. A., Adams, P. F., \& Peregoy, J. A. (2013). Health behaviors of adults: United States, 2008-2010. Vital Health Statistics, 10(257), 44-59.

Schuck, K., Otten, R., Engels, R. C. M. E., Barker, E. D., \& Kleinjan, M. (2012).

Bidirectional influences between parents and children in smoking behavior: A longitudinal full-family model. Nicotine \& Tobacco Research, 15(1), 44-51. doi: $10.1093 / \mathrm{ntr} / \mathrm{nts} 082$

Shoham, A., \& Dalakas, V. (2005). He said, she said... they said: Parents' and children's assessment of children's influence on family consumption decisions. Journal of Consumer Marketing, 22(3), 152-160.

Sixsmith, J., Boneham, M., \& Goldring, J. E. (2003). Accessing the community: Gaining insider perspectives from the outside. Qualitative Health Research, 13(4), 578589. doi: $10.1177 / 1049732302250759$

Stokols, D. (1992). Establishing and maintaining healthy environments. Toward a social ecology of health promotion. Am Psychol, 47(1), 6-22.

Stokols, D. (1996). Translating social ecological theory into guidelines for community health promotion. Am J Health Promot, 10(4), 282-298.

Swinyard, W. R., \& Sim, C. P. (1987). Perception of children's influence on family decision processes. Journal of Consumer Marketing, 4(1), 25-38.

Task Force on Community Preventive Services. (2002). Recommendations to increase physical activity in communities. Am J Prev Med, 22(4S), 67-72.

Timperio, A. F., van Stralen, M. M., Brug, J., Bere, E., Chinapaw, M. J., De Bourdeaudhuij, I., ... Te Velde, S. J. (2013). Direct and indirect associations between the family physical activity environment and sports participation among 
10-12 year-old European children: Testing the EnRG framework in the ENERGY project. Int J Behav Nutr Phys Act, 10, 15. doi: 10.1186/1479-5868-10-15

Trost, S. G., Sallis, J. F., Pate, R. R., Freedson, P. S., Taylor, W. C., \& Dowda, M. (2003). Evaluating a model of parental influence on youth physical activity. Am J Prev Med, 25(4), 277-282.

U. S. Department of Health and Human Services. (1996). Physical activity and health: A report of the surgeon general. Atlanta, GA: US Department of Health and Human Services, Centers for Disease Control and Prevention. National Center for Chronic Disease Prevention and Health Promotion, 147.

U. S. Department of Health and Human Services. (2008). 2008 Physical Activity Guidelines for Americans.

U. S. Department of Health and Human Services Healthy People 2020. (2013). Physical Activity: Overview. Retrieved April 19, 2014, from http://www.healthypeople.gov/2020/topicsobjectives2020/overview.aspx?topicid $=33$

U.S. Department of Health Education \& Welfare. (1979). The Belmont report: Ethical principles and guidelines for the protection of human subjects of research. Washington, DC: OPRR Reports.

United States Census Bureau. (2014). State and County Quickfacts. Retrieved from http://quickfacts.census.gov.

United States Department of Agriculture Economic Research Service. (2011). Kentucky fact sheet. Retrieved from http://www.ers.usda.gov/data. 
Wang, G., Macera, C. A., Scudder-Soucie, B., Schmid, T., Pratt, M., \& Buchner, D. M. (2005). A cost-benefit analysis of physical activity using bike/pedestrian trails. Journal of Health Promotion Practice, 6, 174-179.

Willis, T. A., Ainette, M. G., \& Walker, C. (2008). Health behavior constructs: Theory, measurement, and research from http://cancercontrol.cancer.gov/brp/constructs/index.html

Wilson, G., \& Wood, K. (2004). The influence of children on parental purchases during supermarket shopping. International Journal of Consumer Studies, 28(4), 329336.

World Health Organization. (2010). Global recommendations on physical activity for health. Geneva, Switzerland: WHO.

Wright, M. S., Wilson, D. K., Griffin, S., \& Evans, A. (2010). A qualitative study of parental modeling and social support for physical activity in underserved adolescents. Health Educ Res, 25(2), 224-232. doi: 10.1093/her/cyn043

Zarnett, D., Coyte, P. C., Nauenberg, E., Doran, D., \& Laporte, A. (2009). The effects of competition on community-based nursing wages. Healthc Policy, 4(3), e129-144.

Zecevic, C. A., Tremblay, L., Lovsin, T., \& Michel, L. (2010). Parental Influence on young children's physical activity. Int J Pediatr, 2010, 468526. doi:

$10.1155 / 2010 / 468526$ 
Appendix A

Recruitment Email

\section{Meade Activity Center (MAC) Project Recruitment Email}

Subject Line: Participants Sought for a Research Study on Parent Perceptions of the Meade Activity Center (MAC)

October 6, 2014

Dear Fellow Meade County Resident,

Dr. Kristi King, a professor at the University of Louisville College of Education and Human Development, and Katie Leslie, a doctoral student at the University of Louisville School of Public Health and Information Sciences, and are looking for participants for a research study. You are receiving this email because your child participated in a program through the Meade Activity Center (MAC) and have received it through the MAC's email list.

This study is about parent perceptions of physical activity. If you want take part in this study, you would be assigned to participate in a group conversation with the research team, where you will discuss your experiences with MAC programs and physical activity. This should take approximately 90 minutes of your time, and you will be provided with a meal and a voucher for savings in a future MAC program. Sessions will be scheduled at the Meade County Library around your availability.

Only the researchers, Dr. Kristi King and Katie Leslie, and other MAC parents who sign up will be present at these discussions. All your comments will be kept anonymous and confidential.

Participating is completely voluntary. If you are interested in participating or have any questions about the study, please contact Katie Leslie at (502) 777-1667 or katie.leslie@louisville.edu. If you don’t want to participate, you don't need to do anything.

Please do not hesitate to contact me if you have any questions.

Sincerely,

Aaron Greenwell, MAC Executive Director 
Appendix B

Recruitment Flyer

\section{MAC: Parent P Volunteers for a Research Study!}

Description: We are researching parents' perceptions of physical activity. If your child has participated in any MAC program we would like to talk to you. We are looking for parents to participate in conversations at the Meade County Library. This will take approximately 90 minutes of your time.

- Lunch or dinner will be provided for participants!

- Participants will be entered in a drawing for giveaways!

To sign up or for questions or more information contact:

\section{Katie Leslie}

502-777-1667

katie.leslie@louisville.edu

This study is conducted under the direction of Dr. Kristi King from the University of Louisville

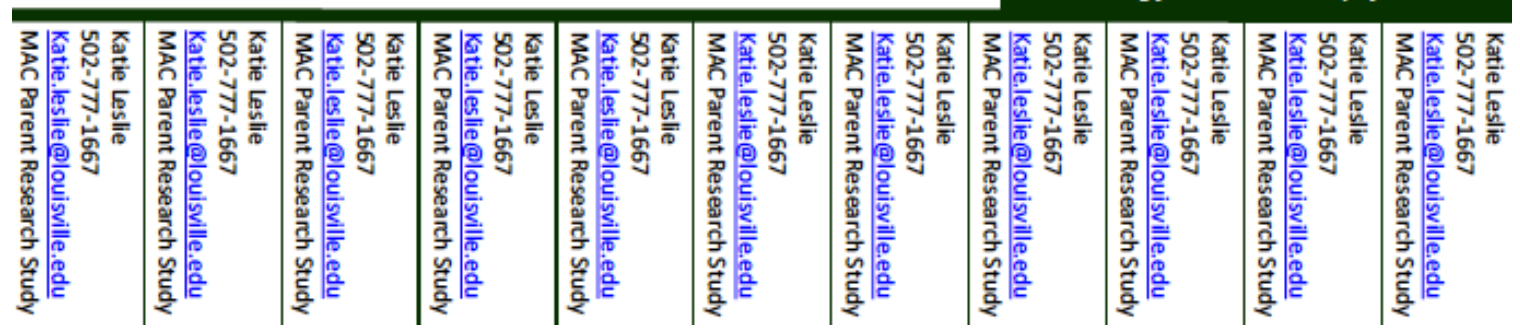




\section{Appendix C}

\section{Interview and Focus Group Guide}

Hello and welcome. My name is Katie and I am a student from the University of Louisville School of Public Health and Information Sciences. This is Dr. King, and she is a teacher from the University of Louisville.

We are conducting a study about the Meade Activity Center. Today, we want to talk with you to learn more about you and your experiences with MAC.

The only people in this room are Dr. King and I from the University of Louisville and yourselves.

Before we start, we need to go over a couple guidelines and go over consent.

We want our discussion to be informal, so there's no need to wait for us to call on you to respond. We also encourage you to respond directly to the comments other people make. We need to be respectful of everyone's opinions and perspectives. There are no right or wrong answers, every comment is important. We wish for everyone to get a chance to talk about something at some point today. Let's try to allow everyone to have a chance to speak.

If you don't understand a question, please let us know and we will try to rephrase the question for you.

At times, we may directly call on people to respond to a question. We are doing this to make sure we get everyone's perspective or opinion on the question. The more feedback we get, the better the study. However, if you do not want to answer a certain question, please let us know and we will respect your decision not to answer.

As you can see, we will be tape recording the discussion and taking notes. We will not be using real names in our conversation today, so when you introduce yourselves and when you comment please use the nickname that you picked and that is on your nametag. If you accidentally say someone's real name today, we will be sure to assign them a nickname when we begin typing up our notes from the tape recordings.

The tapes will be typed up exactly like we hear them from today. All tapes, typed notes, and sheets you filled out today will be kept in my office in a locked file cabinet or on a password- protected computer.

Are there any questions about the discussion today? 
Before we begin the discussion, everyone needs to review a consent form. Let's go over it here. [Review each individual paragraph and sign informed consent documents]

Does everyone understand? [After each paragraph]

Are there any further questions?

Then let's begin. We will start with some general questions about the community, and then ask questions about you and your family's experiences with the MAC.

\section{Introductory Questions}

1. So that we can record your voice for the tape, please around room, introduce yourself by nickname, and tell how long you've lived in Meade County.

2. Tell me about your community. How would you describe your community in terms of physical activity in children and adults. FOLLOW UP- How has that changed over time?

\section{Child PA Behaviors}

1. What types of physical activities do your children do?

2. I'd like you to discuss if the MAC project has influenced your children's physical activity behaviors?

\section{Parent PA Behaviors}

1. What types of physical activities do you do?

2. Tell me about how you and your children are physically active together. FOLLOW UP- How have your children reacted when you've asked them to do some kind of physical activity with you? How have you reacted when your children have asked you to do some kind of physical activity with them?

3. Describe the availability and accessibility of physical activity opportunities for adults here in Meade County.

4. How has your children's involvement in MAC activities affected you? Can you give me some examples?

\section{Final Questions}

1. What didn't I ask you today that you expected me to ask?

Thank you for participating. Does anyone have any final comments or questions?

Next we listen to the tapes from all the focus groups and interviews and analyze the discussions for themes.

If you have any questions, please feel free to contact me. Thank you. 
Appendix D

Demographic Questionnaire

\section{Meade Activity Center and Physical Activity Focus Group Demographic Questionnaire University of Louisville- Fall 2014 \\ **Do not write your name on this document***}

1. Nickname used for today's discussion

2. Age:

3. Gender Male Female

4. Which category best describes your race? (check all that apply) White African American (Black) Native American/ Alaska Native Asian/Pacific Islander Other (Specify)

5. Ethnicity

Hispanic/Latino Non- Hispanic / Latino

6. How long have you lived in Meade County?

7. Highest Level of Education Less than high school diploma High school diploma/GED Some college/technical training

\section{Work Status}

\section{Employed full-time}

Employed part-time or seasonally Unemployed Student

\section{Marital Status}

Single

Married

Unmarried, living with partner
Technical/Associates degree College/University degree or more

Homemaker Retired Other (please specify)

Divorced

Separated 
10. Which MAC programs have YOU participated in? (check all that apply)

Not participated in any programs

Yoga

$5 \mathrm{k}$

Zumba

Mini Triathlon

Other (please specify)

11. On average, how many days per week do YOU accumulate at least $\mathbf{3 0}$ minutes of moderate intensity physical activity (such as brisk walking)?

Less than 1

1

2

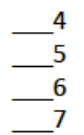

12. The following table contains questions about children living in your home. Please complete the table, answering for each child who lives in your home.

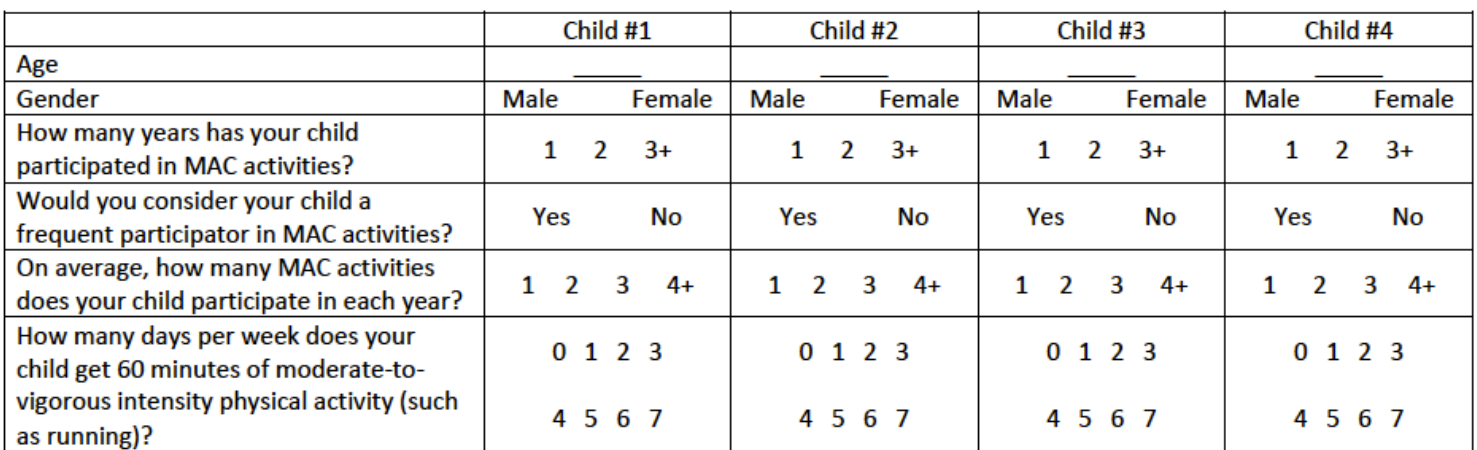


Appendix E

\section{Subject Informed Consent Document The Meade Activity Center (MAC) Project}

IRB assigned number: 11.0558

Investigator(s) name \& address: Kristi King, PhD, CHES; Department of Health and Sport Sciences, University of Louisville, Louisville, KY 40292

Katie Leslie, MS, Department of Health Promotion and Behavioral Sciences, University of Louisville School of Public Health and Information Sciences

Sites where study is to be conducted: Meade County Library

Phone number for subjects to call for questions: Katie Leslie, 502-777-1667

\section{Introduction and Background Information}

You are invited to participate in a research study. The study is being conducted by Dr. Kristi King, PhD, CHES, Principal Investigator, and Katie Leslie, MS, doctoral student. The study is sponsored by the Department of Health and Sport Sciences, University of Louisville College of Education, and the Department of Health Promotion and Behavioral Sciences, University of Louisville School of Public Health and Information Sciences. The study will take place at the Meade County Library. Approximately 100 subjects will be invited to participate.

\section{Purpose}

The purpose of this study is to explore parents' perceptions of physical activity in Meade County.

\section{Procedures}

In this study, you may be asked to participate in a focus group discussion. In this discussion you will be asked about your child's physical activity behaviors and your own physical activity behaviors. This discussion will last a total of approximately 90 minutes. These interviews will be audio recorded. You do not have to answer any questions that make you uncomfortable. You may choose to participate at any time.

\section{Potential Risks}

There are no foreseeable risks other than discomfort in answering personal questions.

\section{Benefits}

The possible benefits of this study include an increase in knowledge about physical activity behaviors. The information collected may not benefit you directly. The information learned in this study may be helpful to others who seek to promote community approaches to increase physical activity.

\section{Compensation}

You will not be compensated for your time, inconvenience, or expenses for your participation in this study. 


\section{Confidentiality}

Total privacy cannot be guaranteed. Your privacy will be protected to the extent permitted by law. If the results from this study are published, your name will not be made public. While unlikely, the following may look at the study records:

The sponsor and companies hired by the sponsor to oversee the study, The University of Louisville Institutional Review Board and Human Subjects Protection Program Office,

People who are responsible for research oversight at the institutions where the study is conducted, and Government agencies, such as Office for Human Research Protections.

All of the paper information collected by Dr. Kristi King and Katie Leslie will be stored in a locked file cabinet in a research office at the University of Louisville. All of the electronic information collected by Dr. King and Katie Leslie will be stored on a secured, password protected computer in encrypted files on a University of Louisville computer. All data will be kept confidential to the extent permitted by law. Should the data from this study be published, all identifiers will continue to be protected.

\section{Voluntary Participation}

Taking part in this study is voluntary. You may choose to not to take part at all. If you decide to be in this study you may stop taking part at any time. If you decide not to be in this study or if you stop taking part at any time, you will not lose any benefits for which you may qualify.

\section{Research Subject's Rights, Questions, Concerns, and Complaints}

If you have any concerns or complaints about the study or the study staff, you have three options.

You may contact the principal investigator at 502-852-8843.

If you have any questions about your rights as a study subject, questions, concerns or complaints, you may call the Human Subjects Protection Program Office (HSPPO) (502) 852-5188. You may discuss any questions about your rights as a subject, in secret, with a member of the Institutional Review Board (IRB) or the HSPPO staff. The IRB is an independent committee composed of members of the University community, staff of the institutions, as well as lay members of the community not connected with these institutions. The IRB has reviewed this study.

If you want to speak to a person outside the University, you may call 1-877-8521167 . You will be given the chance to talk about any questions, concerns or complaints in secret. This is a 24 hour hot line answered by people who do not work at the University of Louisville.

This paper tells you what will happen during the study if you choose to take part. Your signature means that this study has been discussed with you, that your questions have been answered, and that you will take part in the study. This informed consent document 
is not a contract. You are not giving up any legal rights by signing this informed consent document. You will be given a signed copy of this paper to keep for your records.

Signature of Subject/Legal Representative

Date Signed

Signature of Person Explaining the Consent Form (if other than the Investigator)

Signature of Investigator

Date Signed

INVESTIGATOR

PHONE NUMBER

Kristi King, PhD, CHES 502-852-8843

Katie Leslie, MS

502-777-1667 


\section{CURRICULUM VITAE}

Katie F. Leslie

1003 Girard Dr.

Louisville, KY 40222

$502.777 .1667(\mathrm{~h})$

$502.852 .8949(\mathrm{w})$

katie.leslie@louisville.edu

\section{EDUCATION}

Doctor of Philosophy in Public Health Sciences

Degree Expected May 2015

University of Louisville, School of Public Health and Information Sciences

Specialization in Health Promotion

Dissertation: "The Influence of Child Physical Activity Programs on Parent Physical Activity in a Rural Community"

Master of Science in Human Resource Education

December 2008

University of Louisville

Bachelor of Science

August 2007

University of Kentucky

Business Minor

\section{WORK EXPERIENCE}

University of Louisville Health Sciences Center

August 2013-Present

Louisville, Kentucky

Program Director for Diversity and Inclusion- Office of Diversity and Inclusion

- Assist the Assitant Vice President for Health Affairs in developing an open and inclusive environment at the Heath Sciences Center (HSC)

- Provide support with grant preparation, data collection, reports and presentations

- Contribute to the development of policies and programs to attract, retain and promote a diverse workforce for the HSC

- Serve as liason between the four HSC schools to collaborate on diversity programming for faculty, staff, and students

- Coordinate HSC recruitment for minority and underserved students

- Administer, supervise, and evaluate all aspects of health career pipeline programs 
- Provide advising and application development for health career pipeline program participants and alumni, and other disadvantaged students

University of Louisville School of Medicine

January 2009-July 2013

Louisville, Kentucky

Program Coordinator, Sr.- Office of Minority and Rural Affairs

- Coordinated, supervised, and evaluated all aspects of the Professional Education Preparation Program (PEPP) Pre-College Summer Workshop and the MCAT/DAT Review Summer Workshop

- Oversaw summer staff consisting of 15 employees

- Managed annual budgets

- Monitored and tracked progress of summer program participants

- Assisted pre-health students in advising and application development

- Managed database and interpreted outcome statistics for PEPP and MCAT/DAT Review programs

- Recruited Kentucky residents for UofL summer programs through informational sessions and communication with high school and undergraduate staff, students, and administration

- Participated in medical and dental school admissions processes

General Electric

January 2008-December 2008

Louisville, Kentucky

Training Intern- Monogram Experience Center

- Assisted trainers with preparations and classes for weekly experiential marketing sessions executing modules that educate industry professionals on the products of the high-end GE Monogram line of appliances

- Facilitated performance improvement efforts relating to training modules and center development

- Designed and conducted a formative evaluation of the processes and products of the MEC

- Created and executed an online training module for the MEC registration system for regional administrators across the U.S.

- Collected, interpreted, managed, and reported weekly survey data at the completion of each session

- Coordinated registration, travel, hotel, and other accommodations for training groups each week

- Managed communication with and continued marketing to industry professional training participants

\section{ADDITIONAL PROFESSIONAL DEVELOPMENT}

- Cook Ross Inc. \& AAMC Present: Unconscious Bias Train-the-Trainer Program for Healthcare Professions, Harvard University, Boston, MA (March 30 - April 2, 2015)

- Provost's Leadership Academy, University of Louisville, Louisville, KY (January October, 2015) 
- LGBT Health and Wellness Certificate Program, University of Louisville, Louisville, KY (August 2014-April 2015)

- Grant Writing Academy, Arts and Sciences Research Office and School of Interdisciplinary and Graduate Studies, University of Louisville, Louisville, KY (January - March 2014)

- Community Action Poverty Simulation Facilitator Training, Missouri Association for Community Action, St. Louis, MO (November 18-19, 2013)

\section{AWARDS}

- Second Place Public Health Graduate Student Award, 2012 Research! Louisville Poster Competition

- 2008-2009 Outstanding Graduate Student Service Award, University of Louisville College of Education and Human Development

\section{FUNDING OBTAINED}

2015 Jones, V.F. \& Leslie, K.F. (Co-PI) University of Louisville Summer AcademyGEAR UP KY 3.0. Kentucky Council on Postsecondary Education. \$105,000.

2015 Leslie, K.F. Staff Senate Committee Small Grant Award. University of Louisville. $\$ 1,000$.

2014 Jones, V.F. \& Leslie, K.F. (Co-PI) University of Louisville Professional Education Preparation Program. Kentucky Council on Postsecondary Education. $\$ 97,254$.

2014 Leslie, K.F. Assessing the Influence of a Community-Based Children's Physical Activity Intervention on Parents' Health Decision-Making in Rural Kentucky. Commission on Diversity and Racial Equality (CODRE) / School of Interdisciplinary and Graduate Studies Diversity Research Grant for Graduate Students, University of Louisville. $\$ 1,000$.

2014 Jones, V.F. \& Leslie, K.F. Implementing a Community-Based CPR Training Initiative Utilizing Pre-Medical Students as Facilitators. Office of Community Engagement Faculty Grant Program, University of Louisville. \$2,500.

2014 Leslie, K.F. Poverty Simulation Pilot Program. Commission on Diversity and Racial Equality (CODRE), University of Louisville. \$850.

\section{PUBLICATIONS}

Chism, A.B. ${ }^{*}$, Leslie, K.F., Ziegler, C., \& Jones, V.F. (2014). From pipeline to physician: Practice outcomes of the Professional Education Preparation Program. Journal of the Kentucky Medical Association, 112(11), 253-258. 
Leslie, K.F., Jones, V.F., Ziegler, C., Chism, A.B. , Rowland, M.L., Elam, C.L., \& Snyder, C.L. (2014). Academic outcomes of the Professional Education Preparation Program. Journal of the Kentucky Medical Association. 112 (11), 245-251.

*Denotes Students and Residents

\section{CONFERENCE PRESENTATIONS}

Thomas, T.D., Leslie, K.F., and Jones, V.F. (2015, May). The Post-Baccalaureate PreMedical Program: A one-stop shop for nontraditional student needs. Panel presentation at the 2015 Southeastern Regional Meeting of the National Association of Advisors for the Health Professions (NAAHP), New Orleans, LA (upcoming).

Clifton, M.L, Leslie, K.F., \& Quick, R.M. (2015, May). Implementing an interprofessional application development conference for undergraduate pre-health students. Panel presentation at the 2015 Southeastern Regional Meeting of the National Association of Advisors for the Health Professions (NAAHP), New Orleans, LA (upcoming).

Leslie, K.F., Jones, V.F., \& Ziegler, C. (2015, April). Improving student attitudes toward poverty through an interdisciplinary simulation program. Oral presentation at the 2015 AAMC Southern Group on Educational Affairs Conference, Charlotte, NC.

Riff, D.F. \& Leslie, K.F. (2014, November). Walking in another's shoes: Understanding poverty through an academic-community partnership. Panel presentation at the Ninth Annual Kentucky Engagement Conference, Morehead, KY.

Leslie, K.F., Jones, V.F., Ziegler, C., Casey, M.E.", Zolj, A.", Calderon, C.A.", \& Dillon, W.C. (2014, November). Implementing a community-based CPR training initiative utilizing pre-medical students as facilitators. Panel presentation at the Ninth Annual Kentucky Engagement Conference, Morehead, KY.

Leslie, K.F. (2013, March). Advising MAPS: Lessons from the University of Louisville chapter. Workshop presented at the $49^{\text {th }}$ Annual Medical Education Conference of the Student National Medical Association, Louisville, KY.

*Denotes Students and Residents

\section{POSTER PRESENTATIONS}

Simpson, R., Leslie, K.F., Jones, V.F., \& Ziegler, C. (2015, April). Where are they now? Practice locations of health career pipeline program participants. Poster Session at the $11^{\text {th }}$ Annual AAMC Health Workforce Research Conference, Alexandria, VA.

Leslie, K.F., Thomas, T.D., \& Jones, V.F. (2015, April). Student successes and experiences in a post-baccalaureate pre-medical program designed for career changers. 
Poster Session at the 2015 AAMC Northeast and Southern GSA/OSR Joint Regional reMeeting, New Orleans, LA.

Calderon, C.A.", Zolj, A. ${ }^{*}$, Leslie, K.F., Ziegler, C., Jones, V.F., Casey, M.E., \& Dillon, W.C. (2015, April). Where to start with Start the Heart? A comparison of participant age for hands-only CPR training. Poster Session at the $14^{\text {th }}$ Annual New England Science Symposium, Harvard University, Boston, MA.

Zolj, A. ${ }^{*}$, Calderon, C.A. ${ }^{*}$, Dillon, W.C., Leslie, K.F, Jones, V.F., Ziegler, C., \& Casey, M.E. (2014, October). Start the Heart: A community-based approach to increase bystander-initiated CPR in cardiac arrest. Poster Session at the Tenth Annual Meeting of the Kentucky Chapter of the American College of Cardiology, Louisville, KY.

Chism, A.B. , Leslie, K.F., Ziegler, C., \& Jones, V.F. (2014, June). From pipeline to practice, recruiting physicians to underserved regions of Kentucky. Poster Session at the University of Louisville Department of Pediatrics Annual Poster Session, Louisville, KY.

Leslie, K.F., Chism, A.B. , Jones, V.F., Ziegler, C.H., Rowland, M.L., \& Elam, C. (2014, May). From pipeline to practitioner: building a diverse healthcare workforce. Poster Session at the Tenth Annual AAMC Health Workforce Research Conference, Washington, DC.

Leslie, K.F., Jones, V.F., Ziegler, C.H., Chism, A.B.", Rowland, M.L., Elam, C., \& Snyder, C.L. (2014, April). Changing the face of healthcare through pipeline enrichment programs. Poster Session at the Association of American Medical Colleges GDI/GSA/OSR National Meeting, San Diego, CA.

Jones, V.F. Leslie, K.F., \& Rowland, M.L. (2013, September). Diversifying the health career workforce through community partnerships. Poster Session at the Community Engagement Showcase, Louisville, KY.

Leslie, K.F., Buchino, S., Chiaventone, L.A., Forristal, J., Lynch, T., \& LaJoie, A.S. (2013, March). Developing a targeted measles vaccination campaign through the mental models approach to risk communication. Poster Session at the $65^{\text {th }}$ Annual Kentucky Public Health Association Conference, Louisville, KY.

Leslie, K.F. \& Schmidt, W.C. (2012, September). An evidence-based policy analysis for increasing primary care physicians in rural Kentucky. Poster Session at Research! Louisville, Louisville, KY.

*Denotes Students and Residents

\section{PROFESSIONAL SERVICE AND ENGAGEMENT}

APHA Annual Meeting and Exposition

Abstract Reviewer APHA-Student Assembly 
UofL Normalizing Disability Week

Planning Committee Member

Journal of Health Care for the Poor and Underserved

2014, 2015

Manuscript Reviewer

UofL Community Lay Caregiver Appreciation Luncheon

2014

Planning Committee Member

ULSOM Diversity Committee

August 2013-Present

Secretary, Committee Member

UofL HSC Cultural Competency Day

2012- Present

Planning Committee Member, Facilitator

University of Kentucky Area Health Education Center

2012-Present

Summer Enrichment and Research Programs Admissions Committee Member

Multi-cultural Association of Pre-Medical Students

2009-Present

Advisor- University of Louisville Chapter

UofL Post-Baccalaureate Pre-Medical Program

2013-2014

Admissions Committee Member

UofL Great Places to Work Initiative

$2011-2013$

Health and Wellness Committee Member

UofLHealth Promotion Body Awareness Body Appreciation Week

2009-2012

Planning Committee Member

Northwest Area Health Education Center

$2009-2010$

Health Career Advisory Board Member

PROFESSIONAL MEMBERSHIPS

American Public Health Association (APHA)

2014- Present

Kentucky Public Health Association (UofL Chapter)

2010-2013

Vice President (2011-2012 \& 2012-2013 academic years) 